\title{
Pantoea ananatis carotenoid production confers toxoflavin tolerance and is regulated by Hfq-controlled quorum sensing
}

\author{
Okhee Choi ${ }^{1}$, Byeongsam Kang ${ }^{1}$, Yongsang Lee ${ }^{1}$, Yeyeong Lee ${ }^{1}$, and Jinwoo Kim ${ }^{1}$ \\ ${ }^{1}$ Gyeongsang National University
}

October 30, 2020

\begin{abstract}
Carotenoids are widely used in functional foods, cosmetics, and health supplements, and their importance and scope of use are continuously expanding. Here, we characterised carotenoid biosynthetic genes of the plant-pathogenic bacterium Pantoea ananatis, which carries a carotenoid biosynthetic gene cluster (including crtE, X, Y, I, B, and Z) on a plasmid. Reverse transcription-polymerase chain reaction (RT-PCR) analysis revealed that the crtEXYIB gene cluster is transcribed as a single transcript and crtZ is independently transcribed in the opposite direction. Using splicing by overlap extension with polymerase chain reaction (SOE by PCR) based on asymmetric amplification, we reassembled crtE-B, crtE-B-I, and crtE-B-I-Y. Highperformance liquid chromatography confirmed that Escherichia coli expressing the reassembled crtE-B, crtE-B-I, and crtEB-I-Y operons produced phytoene, lycopene, and $\beta$-carotene, respectively. We found that the carotenoids conferred tolerance to UV radiation and toxoflavin. Pantoea ananatis shares rice environments with the toxoflavin producer Burkholderia glumae and is considered to be the first reported example of producing and using carotenoids to withstand toxoflavin. We confirmed that the carotenoid production of P. ananatis is dependent on RpoS, which is positively regulated by Hfq/ArcZ and negatively regulated by ClpP, similar to an important regulatory network of E. coli (HfqArcZ - RpoS ClpXP). We also demonstrated that Hfq-controlled quorum signalling de-represses EanR to activate RpoS, thereby initiating carotenoid production. Survival genes such as those responsible for the production of carotenoids of the plant-pathogenic P. ananatis must be expressed in a timely manner to overcome stressful environments and compete with other microorganisms. This mechanism is likely maintained by a brake with excellent performance, such as EanR.
\end{abstract}

Pantoea ananatis carotenoid production confers toxoflavin tolerance and is regulated by Hfqcontrolled quorum sensing

Okhee Choi $^{1+}$, Byeongsam Kang ${ }^{2+}$, Yongsang Lee ${ }^{2}$, Yeyeong Lee $^{3}$ and Jinwoo Kim ${ }^{1,2,3 *}$

${ }^{1}$ Institute of Agriculture and Life Science, Gyeongsang National University, Jinju 52828, South Korea

${ }^{2}$ Division of Applied Life Science, Gyeongsang National University, Jinju 52828, South Korea

${ }^{3}$ Department of Plant Medicine, Gyeongsang National University, Jinju 52828, South Korea

*For correspondence. E-mail jinwoo@gnu.ac.kr; Tel. (+82) 55772 1927; Fax (+82) 557721929.

+ Okhee Choi and Byeongsam Kang contributed equally to this work.

Running title: Hfq-controlled quorum sensing regulates carotenoid

Keywords : carotenoid, quorum sensing, Pantoea ananatis , Hfq, RpoS, ClpP

\section{SUMMARY}

Carotenoids are widely used in functional foods, cosmetics, and health supplements, and their importance and scope of use are continuously expanding. Here, we characterised carotenoid biosynthetic genes of the plant- 
pathogenic bacterium Pantoea ananatis, which carries a carotenoid biosynthetic gene cluster (including $\mathrm{crtE}$ $, X, Y, I, B$, and $Z$ ) on a plasmid. Reverse transcription-polymerase chain reaction (RT-PCR) analysis revealed that the $\operatorname{crtEXYIB}$ gene cluster is transcribed as a single transcript and $\operatorname{crt} Z$ is independently transcribed in the opposite direction. Using splicing by overlap extension with polymerase chain reaction (SOE by PCR) based on asymmetric amplification, we reassembled $\operatorname{crt} E-B, \operatorname{crt} E-B-I$, and $\operatorname{crt} E-B-I-Y$ . High-performance liquid chromatography confirmed that Escherichia coli expressing the reassembled $\operatorname{crt} E$ $-B, \operatorname{crt} E-B-I$, and $\operatorname{crt} E-B-I-Y$ operons produced phytoene, lycopene, and $\beta$-carotene, respectively. We found that the carotenoids conferred tolerance to UV radiation and toxoflavin. Pantoea ananatis shares rice environments with the toxoflavin producerBurkholderia glumae and is considered to be the first reported example of producing and using carotenoids to withstand toxoflavin. We confirmed that the carotenoid production of $P$. ananatis is dependent on RpoS, which is positively regulated by Hfa/ArcZ and negatively regulated by ClpP, similar to an important regulatory network of $E$. coli ( $\mathrm{Hfq}^{\mathrm{ArcZ}}$ - RpoS ClpXP). We also demonstrated that Hfq-controlled quorum signalling de-represses EanR to activate RpoS, thereby initiating carotenoid production. Survival genes such as those responsible for the production of carotenoids of the plant-pathogenic $P$. ananatis must be expressed in a timely manner to overcome stressful environments and compete with other microorganisms. This mechanism is likely maintained by a brake with excellent performance, such as EanR.

\section{INTRODUCTION}

Carotenoids are widely used in functional foods, cosmetics, and health supplements, and their importance and scope of use are continuously expanding (Song et al ., 2013; Ram et al ., 2020). Carotenoids are produced by plants and microorganisms including algae, fungi, yeast, and bacteria, but animals must obtain carotenoids from dietary sources. Interestingly, aphids, which are capable of synthesising carotenoids, are reported by later gene transfer from fungi (Moran and Jarvik, 2010).

A number of carotenoid-producing bacteria have been identified (Lorquinet al ., 1997; Dufossé et al ., 2005; Sodkova et al ., 2005; Sajilata et al ., 2008; Fasano et al ., 2014; Virtamoet al ., 2014; Lu et al ., 2017; Fidan and Zhan, 2019; Ramet al ., 2020). Carotenoids are highly hydrophobic, restricted to essential parts of the complex membrane and cell wall in bacteria, and mainly responsible for enhancing various functions related to the cell membrane and walls (Kirti et al ., 2014, Lutnaes et al ., 2004, Vila et al ., 2019). Carotenoids enhance various membrane functions, including physical strength, fluidity, cell wall rigidity, and lipid peroxidation. Several functions are closely related to the habitats of bacteria; in particular, the carotenoids of bacterial species living in low- or high-temperature environments are used to control the membrane fluid, while those of bacteria continuously exposed to UV radiation increase tolerance to UV (Kunisawa and Stanier, 1958; Mathews and Sistrom, 1959; Stanier, 1959; Mathew and Sistrom, 1960; Dundas and Larsen, 1963; Mostofian et al ., 2020). In addition, carotenoids aid bacteria in combating stress related to oxidation, salt, and desiccation (Oren, 2009; Tian and Hua, 2010). When bacteria are placed in a stressful environment, carotenoid production increases to protect against particular stressors, such as temperature, salt, light, and acidity (Paliwal et al ., 2017; Ram et al ., 2019). This is consistent with the fact that bacterial carotenoid production is closely related to habitat characteristics.

Pantoea ananatis is considered as an emerging pathogen based on the increasing number of reports of diseases occurring in a wide range of economically important agricultural crops worldwide. This pathogen can also infect humans and numerous insects (Coutinho and Venter, 2009; Dutta et al ., 2016; Weller-Stuart et al ., 2017) and cause bacteremia infection (De Baere et al ., 2004). P. ananatisPA13 causes plant diseases such as rice grain rot, sheath rot, and onion center rot disease in Korea (Choi et al ., 2012a; Choi et al ., 2012b; Kim and Choi, 2012). This pathogen is a potential threat to stable rice production, in particular during the growing season, when the weather is hot and humid.

Quorum sensing (QS) is bacterial cell-to-cell communication with extracellular signalling molecules called autoinducers that are present in the environment in proportion to cell density (Platt and Fuqua, 2010). This system facilitates community coordination of gene expression and benefits group behaviours. QS of $P$. ananatis, which uses EanRI homologous to $P$. stewartii subsp.stewartii EsaRI, has revealed that 
EanR negatively regulates self-expression and EPS production, but not eanI expression (von Bodman and Farrand, 1995; Minogue et al ., 2005; Morohoshiet al ., 2007; Lee, 2015). In P . ananatis , 3-oxo-hexanoyl homoserine lactone (3-oxo-C6AHL) and hexanoyl homoserine lactone (C6AHL) signals are generated by EanI and secreted extracellularly. AHL signals bind EanR, an AHL receptor; this interaction de-represses the EanR negative regulator (Morohoshi et al ., 2007).

The RNA chaperone Hfq and sRNAs are important regulators of virulence in P. ananatis (Kang, 2017; Shin et al ., 2019). Hfq, a ring-shaped hexameric RNA binding protein, has many important physiological roles that are mediated by interaction with Hfq-dependent small RNAs (sRNAs) in bacteria (Brennan and Link, 2007). Hfq was first reported in Escherichia coli as a host factor important in the replication of bacteriophage Q $\beta$ (Muffler et al. , 1996). Hfq regulates the stress response protein RpoS, which controls many stress response genes (Brown and Elliott, 1996; Mandin and Gottesman, 2010; Hwang et al ., 2011); it also regulates virulence in several pathogenic bacteria (Sittka et al ., 2007; Chao and Vogel, 2010; Zeng et al ., 2013). In addition, it modulates a wide range of physiological responses in bacteria. The $h f q$ deletion mutant exhibits several different phenotypes (Figueroa-Bossi et al ., 2006). The Hfq protein interacts with A/U-rich regions of untranslated sRNAs of 50-250 nucleotides with tree stem-loop sequence motifs (Lorenzet al ., 2010) and assists with sRNA base pairing with target mRNA (Beisel and Storz, 2010) and the regulation of gene expression (Vogel and Wagner, 2007; Fröhlich and Vogel, 2009; Bardill and Hammer, 2012). Hfq is required for the functioning of several regulatory sRNAs, including OxyS and RyhB (Storz et al ., 2004; Majdalani et al ., 2005; Aiba, 2007; Gaida et al ., 2013). sRNAs act as activators or repressors of protein translation through complementary base pairing with mRNA in response to change in environmental conditions (Gottesman et al ., 2006; Waters and Storz, 2009; Beisel and Storz, 2010). Several sRNAs regulate RpoS, including ArcZ. ArcZ (also called RyhA and SraH) binds Hfq and positively regulates regulatory RNA, which controls the translation of RpoS (Repila et al ., 2003). ArcZ also regulates virulence, exopolysaccharide (EPS) production, motility, and the hypersensitive response (HR) in bacterial plant pathogens (Papenfort et al ., 2009; Soper et al ., 2010; Baket al ., 2014; Zeng and Sundin, 2014; Schachterle and Sundin, 2019).

Bacteria are surprisingly rich producers of carotenoids. However, bacteria with a low carotenoid content are unsuitable for commercial use. Production of plant-based carotenoids in bacteria is easier than in eukaryotic organisms such as yeasts, fungi, and plants (Ram et al ., 2020). Previously, biosynthesis of carotenoids has relied on bacterial carotenoid genes and DNA recombination techniques. Because these methods depend on restriction sites, generating recombinant DNA fragments and rearranging multiple carotenoid genes is problematic. The technique of splicing by overlap extension by polymerase chain reaction (SOE by PCR) using asymmetric amplification was first developed for introducing mutations into the centre of a PCR fragment (llis et al ., 1986; Higuchi et al ., 1988; Ho et al ., 1989), making site-directed mutagenesis more flexible. Horton et al . (1989) modified SOE by PCR to allow DNA segments from two different genes to be spliced together by overlap extension. SOE has been applied to enhance site-directed mutagenesis (Xiao et al ., 2007; Duan et al ., 2013; Hussain and Chong, 2016), generation of nonpolar, markerless deletions in bacteria (Merritt et al ., 2007; Kim et al ., 2013; Xu et al ., 2013), multiple-site fragment deletion (Zenget al ., 2017), and generation of hybrid proteins of immunological interest (Warrens et al ., 1997).

We reassembled carotenoid genes (crtE , crtB , crtI , and $\operatorname{crt} Y$ ) of P. ananatis using splicing by overlap extension (SOE) to enable production of phytoene, lycopene, and $\beta$-carotene in Escherichia coli . We found that carotenoids were responsible for toxoflavin tolerance in $P$. ananatis. We confirmed that carotenoid production in $P$. ananatis is dependent on RpoS, which is regulated positively by Hfq/ArcZ and negatively by ClpP, similar to an important regulatory network of $E$. coli ( $\mathrm{Hfq}^{\mathrm{ArcZ}}$ - RpoS ClpXP). We also showed that Hfq-controlled quorum signalling de-represses EanR to activate RpoS, thereby initiating carotenoid production.

\section{RESULTS}

Identification of the carotenoid biosynthetic gene cluster inPantoea ananatis PA13

We previously reported the whole genome sequence of $P$.ananatis PA13 (Choi et al ., 2012b), which revealed 
a carotenoid gene cluster on a plasmid (PAGR_p; CP003086). Figure 1 shows the genetic map and putative pathway responsible for carotenoid biosynthesis in $P$. ananatis PA13. The open reading frames (orfs) in the carotenoid biosynthetic gene cluster were analysed and annotated as $\operatorname{crtE}, \operatorname{crt} X, \operatorname{crt} Y, \operatorname{crtI}, \operatorname{crtB}$, and $\operatorname{crt} Z$ in sequence. When comparing the crtgene clusters between $P$. ananatis and the genetically close species $P$. agglomerans, there is a significant difference in the position of $i d i$, which is located in the chromosome in the former strain (PAGR_g2908) and between $\operatorname{crtE}$ and $\operatorname{crt} X$ in the latter. The structure of the other genes is identical in the two strains (Fig. 1A).

The putative carotenoid biosynthetic pathway of $P$.ananatis was inferred from the pathways of Pantoea species (Misawa et al ., 1995; Hundle et al ., 1994) and plants (Guerinot, 2000). Carotenoid biosynthesis begins with isomerisation of isopenthyl diphosphate (IPP) from the mevalonate pathway to produce dimethylallyl diphosphate (DMAPP) in a reaction catalysed by IPP isomerase encoded by $i d i$. Carotenoids are produced from the common precursor farnesyl diphosphate (FPP). Addition of a further IPP molecule yields geranylgeranyl diphosphate (GGPP) in a reaction catalysed by GGPP synthetase (encoded by $c r t E$ ). The next step in the carotenoid pathway is the head-to-head condensation of two molecules of GGPP to produce phytoene in a reaction catalysed by phytoene synthase (encoded by $\operatorname{crtB}$ ). Sequentially, the involved enzymes include phytoene desaturase (encoded by $\operatorname{crtI}$ ), lycopene $\beta$-cyclase $(\operatorname{crt} Y$ ), $\beta$-carotene hydroxylase ( $\operatorname{crt} Z)$, and zeaxanthin glucosyl transferase ( $\operatorname{crt} X)$ (Fig. 1B).

\section{Carotenoid biosynthetic cluster genes crtEXYIB of $\mathrm{P}$. ananatis are polycistronic}

We performed reverse transcription-polymerase chain reaction (RT-PCR) to determine if the wild-type $P$ . ananatis carotenoid biosynthetic cluster genes are polycistronic. We used five sets of primers to amplify crtE $-X, X-Y, Y-I, I-B$, and $B-Z$. RT-PCR followed by Southern hybridisation indicated that the $P$

. ananatis carotenoid biosynthetic cluster genes $\operatorname{crtEXYIB}$ are transcribed as a single transcript, and $\operatorname{crt} Z$ is transcribed as an independent single transcript in the opposite direction (Fig. 2).

\section{Cloning of SOE fragments and RT-PCR analysis}

Each SOE product was TA-cloned into pGEM-T Easy vector (Promega, Madison, WI, USA) and sequenced to confirm the presence of the DNA sequences (Macorgen Inc., Daejeon, South Korea). Next, clones containing $\operatorname{crtEB}, \operatorname{crtEBI}$, or $\operatorname{crtEBIY}$ were digested with Xhol and Sacl and ligated into the corresponding positions of pBBR1MCS5 (Kovach et al ., 1995), generating pYS71, pYS69, or pYS76, respectively (Supplementary Fig. S1).

We used RT-PCR to determine if the reassembled $\operatorname{crtEB}, \operatorname{crtEBI}$, and $\operatorname{crtEBIY}$ clones on the plasmids pYS71, pYS69, and pYS76 are transcribed as a single transcript. We used three sets of primers to amplify crtE $-B, B-I$, and $I-Y$. RT-PCR followed by Southern hybridisation indicated that the reassembled crt $E-B, \operatorname{crt} E-B-I$, and $\operatorname{crt} E-B-I-Y$ clones on the plasmids pYS71, pYS69, and pYS76 are transcribed as single transcripts (Supplementary Fig. S2).

Carotenoid production in E. coli

To determine if $E$. coli DH5 $\alpha$ transformed with pYS71/pSRKGm::crtE - B, pYS69/pSRKGm::crtE $-B-I$, or pYS76/pSRKGm::crtE $-B-I-Y$ produces phytoene, lycopene, or $\beta$-carotene, respectively, we performed high-performance liquid chromatography (HPLC). The results revealed that $E$. coli DH $5 \alpha /$ pYS71/pSRKGm:: crtE $-B$ produced colourless phytoene, as confirmed by the standard peak at the same retention time (Fig. 3A and D); $E$. coliDH5 $\alpha /$ pYS69/pSRKGm::crtE $-B-I$ produced magenta lycopene, as confirmed by the standard peak at the same retention time (Fig. 3B, D); and $E$. coliDH5 $\alpha / \mathrm{pYS76/pSRKGm::crtE}-B-I-Y$ produced orange $\beta$-carotene, as confirmed by the standard peak at the same retention time (Fig. $3 \mathrm{C}, \mathrm{D}$ ). SOE enabled reassembly of multiple carotenoid synthetic genes and the production of carotenoids in $E$. coli .

Carotenoid confers $\mathrm{P}$. ananatis with tolerance to toxoflavin and $U V$ radiation

Toxoflavin is a phytotoxin produced by $B$. glumae, a rice-grain pathogen that shares rice environments 
with $P$.ananatis and has antibacterial properties. To determine if carotenoid production in $P$. ananatis is responsible for tolerance to toxoflavin and UV radiation, we generated a polarised $c r t E$ ::pCOK184 mutant by Campbell insertion (Fig. 4A). Complementation plasmid pCOK218 was also generated by cloning the carotenoid biosynthetic genes $\operatorname{crt} E-Z$ into pBBR1MCS5 (Fig. 4A), which recovered the carotenoid deficiency in thecrtE ::pCOK184 mutant (Fig. 4B). The wild-type is sensitive to toxoflavin concentrations $>20 \mu \mathrm{g} \mathrm{mL} \mathrm{L}^{-1}$ (Fig. 4B). The crtE ::pCOK184 mutant exhibited lower tolerance than the wild-type to $20 \mu \mathrm{g} \mathrm{mL} \mathrm{L}^{-1}$ toxoflavin; however, the wild-type and complementation strain $(+)$ showed greater tolerance than the crtE mutant (Fig. 4B). These results were consistent with those for UV radiation tolerance, but the survival of the crtE ::pCOK184 mutant was approximately 100 times lower than that of the wild-type (Supplementary Fig. S3).

Carotenoid production is dependent on RpoS, which is regulated positively by Hfq/ArcZ and negatively by ClpXP in P. ananatis

Figure 5A shows the HfqArcZ - RpoS ClpXP regulatory networks of $E$. coli. In $E$. coli, the stationary sigma factor RpoS is regulated positively by Hfq and its cognate sRNA ArcZ. RpoS levels are kept low by constitutive degradation of the ClpXP protease until stationary phase (Raju et al ., 2012). RpoSdependent carotenoid production has been previously reported in $P$. agglomerans (Becker-Hapaka et al ., 1997). To determine whether this regulation also occurs in $P$.ananatis, we constructed non-polar mutants of the $r p o S, h f q, \operatorname{arc} Z$, and $c l p P$ genes and generated complementation strains for the corresponding gene mutants. The colonies of [?] rpoS and [?] hfq mutants were white, and neither produced carotenoids (Fig. $5 \mathrm{~B}$ ); however, colonies of complementation strains (+) carrying pCOK312 and pCOK335, respectively, were orange and produced carotenoids. Colonies of the [?] $\operatorname{arc} Z$ mutant were faint orange and exhibited a slight reduction in carotenoid production (Fig. 5B), indicating involvement in carotenoid production. Colonies of the [?] $\operatorname{clp} P$ mutant were dark orange and exhibited an approximately two-fold increase in carotenoid production, indicating negative carotenoid regulation via RpoS inhibition (Fig. 5B). Complementation strains (+) of [?] $\operatorname{arc} Z$ and [?] $\operatorname{clp} P$ mutants carrying pBS28 and pOR78, respectively, produced amounts of carotenoids similar to that of the wild-type. These results suggest that carotenoid production of $P$. ananatis is dependent on RpoS, which is regulated positively by Hfq/ArcZ and negatively by ClpP, similar to an important regulatory network of $E$. coli ( $\left.\mathrm{Hfq}^{\mathrm{ArcZ}}-\mathrm{RpoS} \mathrm{ClpXP}\right)$.

EanR negatively regulates carotenoid production in $\mathrm{P}$. ananatis

A previous report examined EanR de-repression in the QS system of $P$. ananatis, which causes centre rot disease in onion (Morohoshi et al ., 2007). QS of $P$. ananatis PA13 is also similar to that of $P$. stewartii (Minogue et al ., 2005). Supplementary Fig. S4 shows the QS system of $P$.ananatis PA13. The eanR and eanI genes are transcribed in the opposite direction, and the lux box is at the ean $R$ gene promoter region (Supplementary Fig. S4A). To determine if eanI expression is under the control of EanR, we constructed alacZY integration of eanI ::pCOK153 (i.e., pVIK112 carryingeanI truncated at both ends) in PA13L and PA13L[?] eanRmutant backgrounds using Campbell insertion (Supplementary Fig. S4A). QS signal production of the mutants was confirmed using thin-layer chromatography (TLC) and a Chromobacterium indicator strain. TheeanI mutant did not produce QS signals, whereas the eanRmutant did (Supplementary Fig. S4B). The expression of eanI was not decreased in the [?] eanR mutant background or increased by the addition of 3-oxo-C6AHL or C6AHL (Supplementary Fig. S4C). These data indicate that the expression of eanI is not under the control of EanR.

We performed functional phenotypic de-repression of EanR using [?] eanI, [?] eanR, and [?] eanI-R mutants of $P$.ananatis PA13. The [?] eanI mutant exhibited no production of QS signals or carotenoids; however, [?] eanR and [?] eanI-Rmutants produced carotenoids, indicating that EanR negatively regulates carotenoid production by the binding of AHLs to EanR (Fig. 6A-C). Carotenoid production of the [?] eanI- $R$ mutant was abolished by transformation with pCOK199 (pBBR1MCS5::Plac - eanR), confirming that EanR negatively regulates carotenoid production (Fig. 6B, C).

EanR negatively regulates carotenoid production via inhibition of rpoS in P. ananatis 
To determine if rpoS expression is regulated by EanR, we constructed a lac $Z Y$ integration of rpoS ::pYS88 (pVIK112 carrying rpoS truncated at both ends) in PA13L, PA13L[?] eanI , PA13L[?] eanR, and PA13L[?] eanI- $R$ mutant backgrounds using Campbell insertion. The expression of rpoS decreased significantly in the [?] eanI mutant background.rpoS expression increased in the [?] eanR and [?] eanI-Rmutant backgrounds (Fig. 6D); rpoS expression decreased in the presence of EanR. These results indicate that EanR negatively regulatesrpoS expression and QS signals de-repress EanR. Although the putative lux box suggests that EanR binds to the promoter region of rpoS (Fig. 6E), there is currently no direct evidence for this. We analysed the candidate lux box(s) in the crtEXYIBgene cluster or the promoter region of the $\operatorname{crtZ}$ gene, but did not find it.

$Q S$ is delayed in the absence of $H f q$

To elucidate the relationship between Hfq and QS, we performed QS signal-production assays with wildtype, [?] $h f q$ mutant, and [?] $h f q$ complementation strains. QS signals were extracted in the mid/late log phase $\left(\mathrm{OD}_{600}=0.9,1.5\right.$ and 1.8) and developed on $\mathrm{C}_{18}$ reversed-phase TLC plates. QS signalling in the [?] $h f q$ mutant (-) decreased significantly but recovered to the level of the wild-type after transforming with pCOK335 (+; pLAFR3::hfq ) (Fig. 7A, B). These results suggest that Hfq positively regulates QS signal production. We also examined whether the reduction in QS signal in the [?] $h f q$ mutant was due to bacterial growth; our results showed that growth in [?] $h f q$ was not retarded compared with the wild-type strain (data not shown). Using $\beta$-galactosidase activity assays, we found that expression of eanI decreased significantly in the absence of Hfq (-) but recovered by transformation with pCOK335 (+; pLAFR3::hfq) (Fig. 7C). This is consistent with the finding that QS signal production in the [?]hfqmutant was significantly lower (Fig. 7A, B). These results indicate that Hfq positively regulates QS, which is delayed in the absence of Hfq in $P$. ananatis .

\section{DISCUSSION}

Pantoea ananatis is an emerging plant pathogen that causes severe loss of many crops and trees, such as maize, onion, rice, and Eucalyptus, worldwide (Coutinho and Venter, 2009; Weller-Stuart et al ., 2017). This bacterium has also been associated with insects and humans. It is considered as a pathogen that is being revised because of its virulence in a wide variety of plant hosts and saprophytic ability in diverse ecological niches (Coutinho and Venter, 2009). In this study, we focused on the carotenoid biosynthesis gene cluster of $P$. ananatis and performed gene reassembly for carotenoid production. Here, we investigated the ecological and physiological functions of regulatory mechanisms of the carotenoid production of $P$. ananatis .

Much effort has focused on the biosynthesis of carotenoids using bacterial carotenoid genes (Misawa et al ., 1995; Guerinot, 2000; Lee et al ., 2003; Mijts and Schmidt-Dannert, 2003). Techniques based on recombining DNA sequences rely on restriction sites, so the primer must contain the introduced restriction site, which should not be in the centre of the fragment (llis et al ., 1986; Higuchiet al ., 1988; Ho et al ., 1989; Horton et al .,1989). Moreover, if multiple cloning vectors are to be used, plasmid incompatibility is also a limiting factor. Here, we applied a SOE by PCR technique to recombine DNA sequences without relying on restriction sites. In this report, we describe the reassembly of the genes encoding bacterial carotenoid biosynthetic proteins as $c r t E-B$, crtE-B-I, or $\operatorname{crt} E-B-I-Y$ for the synthesis of phytoene, lycopene, or $\beta$-carotene, respectively. $E$. coli expressing $\operatorname{crt} E-B$, crtE-B-I , or $\operatorname{crt} E-B-I-Y$ produced phytoene, lycopene, or $\beta$-carotene, respectively. Zeaxanthin biosynthesis was enabled by the addition of $\operatorname{crt} Z$, but gene recombination failed despite numerous attempts. It seems that the likelihood of success decreases with increasing number of genes to be recombined.

In practice, simply introducing lacZ ribosomal binding sequences (RBSs) at the beginning of the SOE$\mathrm{AB}$ product (Plac - crtE) enables carotenoid biosynthesis. CrtE catalyses the synthesis of GGPP, an early intermediate of carotenoid biosynthesis. We did not test whether the absolute amount of carotenoids increases as the level of GGPP increases in vivo .

We used a DNA template from the rice pathogenic bacterium $P$.ananatis in SOE by PCR, which is controllable and independent of restriction sequences, for carotenoid gene reassembly. Pantoea agglomerans, which causes palea browning of rice, is a genetically close species to $P$. ananatis with which it shares a biological 
niche. The organisation of the carotenoid biosynthetic gene clusters of the two strains is identical, except $i d i$. Interestingly, $P$. agglomerans has an $i d i$ gene between $c r t E$ and $c r t X$, which distinguishes it from $P$. ananatis, suggesting that $i d i$ could be used to distinguish genetically similar bacteria.

SOE is a novel PCR-mediated recombinant DNA technology that does not rely on restriction sites, so its coverage is considerably wider than standard restriction enzyme-based methods for gene recombination. This enables finer control over recombination for genetic engineering. In addition, the sequence of the overlap region is determined by primer design, allowing simultaneous non-polar mutagenesis, site-directed mutagenesis, and recombination. In this study, we applied this technically simple and rapid recombinant DNA technique to the biosynthesis of three carotenoids. The technique will likely be suitable for recombination of multiple genes.

In bacteria, carotenoids are closely related to the conditions of the surrounding environment. We found that the UV radiation tolerance of $P$. ananatis was due to the carotenoids they produce. These results are consistent with those regarding $P$. stewartiisubsp. stewartii (Mohammadi et al ., 2012). Considering the plant environment (particularly rice) in which $P$. ananatislives, UV radiation tolerance is advantageous for survival. Interestingly, these carotenoids are unique in that they also make $P$. ananatis tolerant to toxoflavin. Thus, tolerance to toxoflavin via carotenoid production can be considered a survival strategy of $P$. ananatis - Bacteria that produce carotenoids have advantages for overcoming environmental stresses, such as UV radiation, salt, and low temperatures. Pantoea ananatis and $B$. glumae share the same rice environment and are the first reported cases of the production and use of carotenoids to overcome toxoflavin.

We found that QS and Hfq are directly or indirectly involved in regulating carotenoid production in $P$. ananatis PA13. QS regulates an extensive range of functions, including bioluminescence, virulence, biofilm formation, DNA exchange, and sporulation in bacteria (Fuqua et al ., 1996, Waters and Bassler, 2005). Hfa is a global RNA chaperone that interacts with sRNAs of diverse functions; it also regulates of virulence and environmental stress in many plant and animal bacterial pathogens (Ding et al ., 2004; Chao and Vogel, 2010; Zeng et al ., 2013; Shin et al ., 2019). The hfqmutant in Erwinia amylovora Ea1189 reduces virulence, amylovoran EPS production, biofilm formation, motility, and positive regulation of the type III secretion system (Zeng et al ., 2013). InPectobacterium carotovorum, the hfq mutant exhibits defects in motility, biofilm formation, sedimentation, and virulence (Wang et al ., 2018). Hfq is also an important regulator of virulence, motility, and biofilm formation in P. ananatis LMG2665 (Shin et al ., 2019). We found that Hfq regulates the expression of eanI encoding the QS signal synthase, which was confirmed byeanI expression and QS signal productivity assays. These results are consistent with the finding that Hfq regulates QS signal production directly via interactions with the AHL receptor ExpR inSinorhizobium meliloti (Gao et al ., 2015). QS systems integrate other global regulators, including noncoding sRNAs. This network is activated through the binding of Hfq and Hfq-dependent sRNA and controls gene expression via post-transcription regulation (Storzet al ., 2005). There are several reports that the Hfq-dependent sRNAs Qrr1-4 and RsmY interact with Hfq to directly and indirectly control QS targets in Vibrio cholerae and Pseudomonas aeruginosa (Lenz et al ., 2004; Kay et al ., 2006). Shinet al . (2019) suggested that the putative Hfq-dependent sRNAs pPAR237 and pPAR238 are involved in regulating QS by activating EanI without genetic analyses. Further studies are needed to identify the sRNAs in P. ananatis . It was previously reported that EanR mediated QS regulation by de-repression as in P. stewartii (von Bodman and Farrand, 1995; Morohoshi et al ., 2007). In P. ananatis, EanR represses the ean box (lux box-like sequences) in the upstream region of eanR, and adding AHL promoted dose-dependent de-repression (Morohoshi et al ., 2007). This EanR-mediated QS regulation was similar to that of the close homolog EsaR in P. stewartii (Minogue et al ., 2005). Overall, we found that QS signal production in $P$. ananatiswas delayed in the absence of Hfq, since EanR negatively regulates RpoS. Expression of RpoS is entirely dependent on bacterial growth. Using EanR, $P$. ananatis must inhibit RpoS expression before reaching stationary phase, at which point EanR is removed to initiate expression of RpoS. Hfq is responsible for determining the timing of the Hfq-mediated increase in eanI expression to produce full QS signals. The resulting QS signals de-repress EanR, followed by Hfq to express RpoS, which turns on carotenoid biosynthesis. 
We found that RpoS regulates carotenoid biosynthesis under the control of Hfq, QS, and ClpP. The regulatory networks of $\mathrm{Hfq}^{\mathrm{ArcZ}}$ - RpoS ClpXP for carotenoid production are similar to those of $E$. coli . Here, we elucidated a regulatory network of carotenoid production involving Hfq-dependent QS-RpoS in $P$. ananatis . Hfq regulates full production of QS signals, thereby de-repressing the EanR negative regulator to initiate RpoS expression (Fig. 8).

\section{EXPERIMENTAL PROCEDURES}

\section{Bacterial strains and plasmids}

Bacterial strains and plasmids used in this study are listed in Supplementary Table S1. E . coli strains were cultured on Luria-Bertani (LB) medium at $37^{\circ} \mathrm{C}$. The $P$. ananatis PA13 was cultivated at $28^{\circ} \mathrm{C}$ on LB medium. Antibiotics were used at the following concentrations: ampicillin, $100 \mu \mathrm{g} \mathrm{mL} \mathrm{L}^{-1}$; kanamycin, 50 $\mu \mathrm{g} \mathrm{mL}{ }^{-1}$; rifampicin, $50 \mu \mathrm{g} \mathrm{mL} \mathrm{m}^{-1}$; tetracycline, $10 \mu \mathrm{g} \mathrm{mL}^{-1}$; gentamycin, $25 \mu \mathrm{g} \mathrm{mL}{ }^{-1}$. 5-Bromo-4-chloro-3indoyl-b-D-galactopyranoside (X-gal) was used at $40 \mu \mathrm{g} \mathrm{mL}{ }^{-1}$ when necessary.

\section{DNA manipulation and data analyses}

Manipulation of genomic DNA and plasmids and DNA cloning were performed as described by Sambrook and Russell (2001). Restriction enzymes (TaKaRa) were used for DNA digestion and modification. DNA sequencing was performed by Macrogen (Seoul). DNA sequences were analyzed with the BLAST program at the National Center for Biotechnology Information (Gish and States, 1993), MEGALIGN (DNASTAR, Madison, WI, USA), and GENETYX-WIN software (Genetyx).

\section{Carotenoid genes}

Genomic DNA of $P$. ananatis PA13, a bacterial pathogen of rice, was used as the template to amplify carotenoid biosynthetic genes. The carotenoid genes are located on a plasmid (PAGR_p; CP003086). Figure 1 shows the carotenoid gene clusters of $P$. ananatisPA13 and $P$. agglomerans Eho10 (M87280; Hundle et al ., 1994).

\section{Strategy for carotenoid gene reassembly}

The reassembly of the carotenoid genes responsible for synthesising phytoene, lycopene, and $\beta$-carotene was performed as described previously (Horton et al ., 1995). The sequences of the eight primers used for reassembly are listed in Supplementary Table S2. Primers 'a' and 'd', 'a' and 'f', and ' $a$ ' and ' $h$ ' are the flanking primers for PCR amplification of the final reassembled products. Primers 'b' and 'c', 'd' and 'e', and ' $\mathrm{f}$ ' and ' $\mathrm{g}$ ' are the SOE primers. Bases have been added to the 5' ends of the primers in each pair to render them complementary. All of the complementary sequences have been added between primers b-c, d-e, and f-g. During SOE, the upper strands of AB and the lower strands of CD overlap to act as primers (Supplementary Fig. S5). Fragment AB was PCR amplified from $\operatorname{crtE}$, and fragment CD from crtB . Fragment EF was PCR amplified from crtI, and fragment GH from crtY. The SOE primers 'b' and 'c' were used to modify the PCR products of two sequences to have an identical sequence (Supplementary Table S2). Supplementary Fig. S5B shows the reassembly of $\operatorname{crt} E-B$ genes for phytoene biosynthesis. The upper strands of $\mathrm{AB}$ and the lower strands of $\mathrm{CD}$ overlap to act as primers when the PCR products are mixed, denatured, and reannealed during PCR. Fragments of AD are formed when this overlap is extended by polymerase. Supplementary Fig. S5C shows the $\operatorname{crt} E-B-I$ gene reassembly for lycopene biosynthesis in which the upper strands of $\mathrm{AD}$ and the lower strands of EF overlap to act as primers when the PCR products are mixed, denatured, and reannealed during PCR. Fragments of AF are formed when this overlap is extended by polymerase. Similarly, the upper strands of AF and the lower strands of GH overlap to act as primers when the PCR products are mixed, denatured, and reannealed during PCR. Fragments of AH are formed when this overlap is extended by polymerase (Supplementary Fig. S5D). The XhoI recognition sequence and lac $Z$ RBS were introduced at the beginning of the SOE-AB products.

SOE by PCR 
SOE by PCR was carried out using a T100 Thermal Cycler (Bio-Rad, Hercules, CA, USA) for 20 cycles, each of $1 \mathrm{~min}$ at $98^{\circ} \mathrm{C}, 1 \mathrm{~min}$ at $55^{\circ} \mathrm{C}$, and $2 \mathrm{~min}$ at $70^{\circ} \mathrm{C}$. The reaction was carried out in a $50 \mu \mathrm{L}$ volume containing 2.5 U Phusion High-Fidelity DNA polymerase (Pfu; Thermo Fisher Scientific), $200 \mu \mathrm{M}$ dNTPs, $1 \mu \mathrm{L}$ of primer mix (1.5 pmol per primer), and $5 \mu \mathrm{L}$ of $10 \times$ Pfu buffer.

Purification and cloning of SOE fragments

The SOE products for use as templates were purified by electrophoresis in agarose $(0.8 \%$ agarose, Promega) in TAE buffer ( $40 \mathrm{mM}$ Tris-acetate, $1 \mathrm{mM}$ ethylenediaminetetraacetic acid) with $0.5 \mu \mathrm{g} \mathrm{mL} \mathrm{m}^{-1}$ ethidium bromide. DNA was recovered from the gel fragment using a DNA Purification Kit (GeneAll, Seoul, South Korea). The final recombinant products were gel purified prior to cloning.

The SOE products were TA cloned into pGEM-T Easy (Promega) and sequenced by Macrogen Services (Daejeon, South Korea). Error-free clones were digested with Xho l and Sac l and ligated into the corresponding positions in pBBR1MCS5 (Kovach et al ., 1995).

RT-PCR analysis of wild-type P. ananatis carotenoid cluster genes

Wild-type $P$. ananatis PA13 was grown in LB medium to exponential growth phase (12 h after inoculation); total RNA was isolated using an RNeasy Mini Kit according to the supplier's instructions (Qiagen); and the RNA samples were treated with RQ1 DNase (Promega) to remove any contaminating DNA. RT-PCR was performed according to a previous report (Kim et al ., 2004) as follows. Total RNA from P . ananatis PA13 was reverse transcribed into cDNA using M-MLV reverse transcriptase as described by the manufacturer (Promega) at $50^{\circ} \mathrm{C}$ for $1 \mathrm{~h}$, followed by $5 \mathrm{~min}$ at $75^{\circ} \mathrm{C}$. Next, PCR was performed using a T100 Thermal Cycler (Bio-Rad) under the following conditions: $96^{\circ} \mathrm{C}$ for $2 \mathrm{~min}$, followed by 40 cycles of $96^{\circ} \mathrm{C}$ for $1 \mathrm{~min}$, $50^{\circ} \mathrm{C}$ for $1 \mathrm{~min}$, and $72^{\circ} \mathrm{C}$ for $1 \mathrm{~min}$. The following primers were used for RT reactions, RT1 (crtB) and RT2 (crtZ ). The following PCR primers were used: PCR1f and PCR1r; PCR2f and PCR2r; PCR3f and PCR3r; PCR4f and PCR4r; and PCR5f and PCR5r (Supplementary Table S3). Southern hybridisation and DNA sequencing were carried out to confirm the RT-PCR products. As a positive control, pCOK218 DNA was used. As a negative control, PCR reactions with the same primer sets were performed using RNA samples that had not been reverse transcribed.

\section{RT-PCR analysis of reassembled carotenoid cluster genes}

$E$. coli harbouring recombinant pYS71, pYS69, or pYS76 was grown in LB medium to exponential growth phase (12 h after inoculation). The following primers were used for RT reactions: RT3 (crtZ ); RT4 (crtI ); and RT5 ( $\operatorname{crt} Y$ ). The following PCR primers were used: PCR6f and PCR6r; PCR7f and PCR7r; and PCR8f and PCR8r (Supplementary Table S3). Southern hybridisation and DNA sequencing were carried out to confirm the RT-PCR products. As positive controls, pYS71, pYS69, and pYS76 were used. As a negative control, PCR reactions with the same primer sets were performed using RNA samples that had not been reverse transcribed.

\section{$H P L C$}

For carotenoid extraction and HPLC analysis, transformed $E$.coli DH5 $\alpha$ harbouring pYS71, pYS69, or pYS76 was cultured in $250 \mathrm{~mL}$ flasks containing $50 \mathrm{~mL}$ of $\mathrm{LB}$ broth with $25 \mu \mathrm{g} \mathrm{mL}{ }^{-1}$ gentamycin at $37^{\circ} \mathrm{C}$ for $24 \mathrm{~h}$. After centrifugation at $10,000 \times g$ for $10 \mathrm{~min}$, the cultured cells were repeatedly extracted with $3 \mathrm{~mL}$ of acetone for lycopene and $\beta$-carotene or ethanol for phytoene until colour was completely lost. The extracted solution was centrifuged and filtered through a GHP membrane $(0.45 \mu \mathrm{m}$ pore size). HPLC was performed using $20 \mu \mathrm{L}$ of prepared sample, with solvent A (60\% acetonitrile, $38 \%$ ethyl acetate, $2 \%$ acetic acid) and solvent $\mathrm{B}\left(100 \%\right.$ methanol) as the mobile phase, on a $\mathrm{C}_{18}$ Shim-pack GIS-DOS column $(4.6 \times 250$ $\mathrm{mm}, 5 \mu \mathrm{m}$; Shimadzu) as a fixed phase at a flow rate of $1.5 \mathrm{~mL} \mathrm{~min}{ }^{-1}$. $\beta$-Carotene was measured at $450 \mathrm{~nm}$ using a photodiode array detector. Lycopene was measured at $470 \mathrm{~nm}$ and phytoene at $280 \mathrm{~nm}$. Phytoene, lycopene, and $\beta$-carotene standards were purchased from Sigma-Aldrich, Inc.

Generation of lacZY-integrations and non-polar deletion mutants 
lacZY transcriptional integration mutagenesis (Campbell insertion) was performed as previously reported (Xu et al ., 2013). An internal DNA fragment of eanI was amplified with EanI-1E-1 and EanI-2K (Supplementary Table S3). The partial eanIfragment was purified, cloned into pGEM-T Easy (Promega), and confirmed by sequencing. For recombinational mutagenesis, the EcoRI/KpnI-digestedeanI fragment was cloned into the pVIK112 suicide vector (Kalogeraki and Winans, 1997), creating pCOK153. The parent strain PA13 was conjugated with pCOK153, and kanamycin-resistant colonies were selected. The mutants were confirmed through PCR using a primer that anneals upstream of the truncated fragment and the primer LacFuse followed by sequencing. We constructed rpoS and crtE null mutants using the same method as described previously.

Non-polar deletion mutagenesis was performed as previously reported (Xuet al ., 2013). We amplified upstream and downstream fragments (approximately $450 \mathrm{bp}$ ) of the targeted gene region by PCR using the corresponding primer pairs (Supplementary Table S3). After purification, the fragments were fused by overlap PCR. The final PCR products were cloned into pGEM-T Easy and confirmed by DNA sequencing. The fragments were excised using appropriate restriction enzymes and ligated into the suicide vector pNPTS138R6KT (Lassak et al ., 2010). The resulting plasmids were introduced into PA13 by conjugative mating, and mating cells were spread on LB medium containing kanamycin and rifampicin. Single-crossover integrates were selected on LB plates containing kanamycin and rifampicin. Single colonies were grown overnight in LB with rifampicin $\left(25 \mu \mathrm{g} \mathrm{mL} \mathrm{m}^{-1}\right)$ and plated on $\mathrm{LB}$ containing $5 \%(\mathrm{w} / \mathrm{v})$ sucrose to select for plasmid excision. We checked kanamycin-sensitive colonies for targeted deletion with colony PCR using primers bracketing the location of the deletion.

\section{Gene complementation}

To generate target gene complementary strains, we cloned each intact target gene into the broad host range plasmid vectors pBBR1MCS5 (Kovachet al ., 1995), pSRKGm (Khan et al ., 2008) or pLAFR3 (Keenet al ., 1988), generating pCOK218 (pBBR1MCS5::crtEXYIBZ), pCOK197 (pBBR1MCS5:: $\mathrm{P}_{\text {lac }}$-eanI), pCOK199

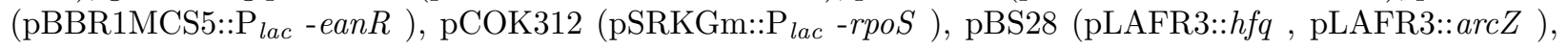
or pOR78 (pBBR1MCS5:: $\mathrm{P}_{l a c}-c l p P$ ) which were transferred to the corresponding mutant strains by conjugation (Supplementary Table S1).

\section{Toxoflavin and $U V$ radiation tolerance}

Overnight cultures of the PA13 derivatives were sub-cultured and grown for an additional $12 \mathrm{~h}$. A 100- $\mu \mathrm{L}$ aliquot was removed and serially diluted 10 -fold, and $10-\mu \mathrm{L}$ of each culture was spotted on LB agar plates supplemented with $20 \mu \mathrm{g} \mathrm{mL}-1$ toxoflavin. The spotted plates were incubated at $28^{\circ} \mathrm{C}$ for $36 \mathrm{~h}$.

For the UV radiation tolerance assays, PA13 derivatives were spotted on LB plates using the above procedure and treated as previously described (Mohammadi et al ., 2012).

\section{Carotenoid production}

To determine the carotenoid content of cells, $P$. ananatis strains were grown in $5 \mathrm{~mL}$ of LB medium at $28^{\circ} \mathrm{C}$. Cells were harvested by centrifugation at $10,000 \times g$ for $1 \mathrm{~min}$ and suspended in $1 \mathrm{ml}$ of methanol. The samples were vortexed for $10 \mathrm{~min}$ and centrifuged at 10,000 $\times \mathrm{g}$ for $10 \mathrm{~min}$, and the methanol supernatant containing carotenoids was transferred to a new tube. We quantified the carotenoid content of the extracts by measuring the absorbance at $450 \mathrm{~nm}$ using a Genesys 10S UV-VIS spectrophotometer (Thermo Fisher Scientific).

\section{AHL signal assay}

The isolation and purification of AHLs were performed as described by Kim et al . (2004). The culture supernatants from time course cultures of $P$. ananatis PA13 and mutants were extracted with ethyl acetate (1:1). The ethyl acetate layer was dried, and the residue was dissolved in methanol. The ethyl acetate extracts were applied to $\mathrm{C}_{18}$ reversed-phase TLC plates (Merck) and developed with $60 \%$ methanol. The TLC plates 
were dried in a fume hood and overlaid with soft agar containing Chromobacterium violaceum CV026 cells cultured overnight. The plates were incubated at $28^{\circ} \mathrm{C}$ overnight.

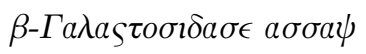

We generated non-polar deletions of lacZY genes from wild-type PA13 named PA13L and confirmed that all traits were identical in the two strains. Wild-type and mutant backgrounds used in the $\beta$-galactosidase assays were PA13L. All of the test strains were grown for $20 \mathrm{~h}$ and sub-cultured in LB broth at $28^{\circ} \mathrm{C}$. The assays were performed with exponential-phase cultures at an $\mathrm{OD}_{600}$ of $\sim 0.4$ as described previously (Choi et al ., 2019).

\section{CONCLUSION}

Microbial biotechnology allows bacterial carotenoids to be used as alternatives to plant-based carotenoids because of the ease of genetic manipulation of prokaryotes compared with eukaryotes, such as yeasts, fungi, and plants. Here, we used SOE by PCR for gene reassembly to redirect carotenoid synthesis from the plant-pathogenic bacteriumPantoea ananatis. Using SOE by PCR, we reassembled $\operatorname{crt} E-B$, crt $E-B-I$, and $\operatorname{crt} E-B-I-Y$ for phytoene, lycopene, and $\beta$-carotene production, respectively, using $E$. coli to express the reassembled operons. We found that carotenoids confer tolerance to the phytotoxin toxoflavin. The carotenoid production of $P$.ananatis is dependent on RpoS, which is regulated positively by $\mathrm{Hfq} / \mathrm{ArcZ}$ and negatively by ClpP, similar to an important regulatory network of $E$. coli , Hfq ${ }^{\text {ArcZ }}$ - RpoS ClpXP. We also demonstrated that carotenoid production is regulated by Hfq-controlled QS, since the EanR negative regulator on RpoS must be expressed in the stationary phase.

\section{Acknowledgment}

This research was supported by Basic Science Research Program through the National Research Foundation of Korea (NRF) funded by the Ministry of Education (2015R1A6A1A03031413).

\section{Conflict of interest}

The authors declare no conflict of interest.

\section{References}

Aiba, H. (2007). Mechanism of RNA silencing by Hfq-binding small RNAs.Curr Opin Microbiol 10 : 134139.

Bak, G., Han, K., Kim, D., and Lee, Y. (2014). Roles ofrpoS -activating small RNAs in pathways leading to acid resistance of Escherichia coli . Microbiologyopen 3 : 15-28.

Bardill, J. P., and Hammer, B. K. (2012). Non-coding sRNAs regulate virulence in the bacterial pathogen Vibrio cholerae. RNA Biol 9 : 392-401.

Bassler, B. L., and Losick, R. (2006). Bacterially speaking. Cell.125 : 237-246.

Beck von Bodman, S. B., and Farrand, S. K. (1995). Capsular polysaccharide biosynthesis and pathogenicity in Erwinia stewartii require induction by an N-acylhomoserine lactone autoinducer. $J$ Bacteriol 177 : 50005008 .

Becker-Hapaka, M., Troxtel, E., Hoerter, J., and Eisenstark, A. (1997). RpoS dependent overexpression of carotenoids from Erwinia herbicola in OXYR defficient Escherichia coli . Biochem Biophys Res Commun 239 : 305-309.

Beisel, C. L., and Storz, G. (2010). Base pairing small RNAs and their roles in global regulatory networks. FEMS Microbiol Rev34 : 866-882.

Brennan, R. G., and Link, T. M. (2007). Hfq structure, function and ligand binding. Curr Opin Microbiol $10: 125-133$. 
Brown, L., and Elliott, T. (1996). Efficient translation of the RpoS sigma factor in Salmonella typhimurium requires host factor I, an RNA-binding protein encoded by the $h f q$ gene. $J$ Bacteriol178 : 3763-3770.

Chao, Y., and Vogel, J. (2010). The role of Hfq in bacterial pathogens.Curr Opin Microbiol 13 : 24-33.

Choi, O., Bae, J., Kang, B., Lee, Y., Kim, S., Fuqua, C., and Kim, J. (2019). Simple and economical biosensors for distinguishingAgrobacterium -mediated plant galls from nematode-mediated root knots. Sci Rep 9 : 17961.

Choi, O., Kim, H., Lee, Y., Kim, J., Moon, J., and Hwang, I. (2012a). First report of sheath rot of rice caused by Pantoea ananatis in Korea. Plant Pathol J 28 : 331.

Choi, O., Lim, J. Y., Seo, Y.-S., Hwang, I., and Kim, J. (2012b). Complete genome sequence of the rice pathogen Pantoea ananatisstrain PA13. J Bacteriol 194 : 531.

Coutinho, T. A., and Venter, S. N. (2009). Pantoea ananatis : an unconventional plant pathogen. Mol Plant Pathol 10 : 325-335.

De Baere, T., Verhelst, R., Labit, C., Verschraegen, G., Wauters, G., Claeys, G., Vaneechoutte, M. (2004). Bacteremic infection withPantoea ananatis. J Clin Microbiol 42 : 4393-4395.

Ding, Y., Davis, B. M., and Waldor, M. K. (2004). Hfq is essential for Vibrio cholera virulence and downregulates sigma expression. Mol Microbiol 53 : 345-354.

Dutta, B., Gitaitis, R., Barman, A., Avci, U., Marasigan, K., and Srinivasan, R. (2016). Interactions between Frankliniella fuscaand Pantoea ananatis in the center rot epidemic on onion (Allium cepa). Phytopathology 106 : 956-962.

Duan, X., Chen, J., and Wu, J. (2013). Improving the thermostability and catalytic efficiency of Bacillus deramificans pullulanase by site-directed mutagenesis. Appl Environ Microbiol 79 : 4072-4077.

Dufossé, L., Galaup, P., Yaron, A., Arad, S. M., Blanc, P., Murthy, K. N. C., and Ravishankar, G. A. (2005). Microorganisms and microalgae as sources of pigments for food use: a scientific oddity or an industrial reality?. Trends Food Sci Technol 16. 389-406.

Dundas, I. D., and Larsen, H. (1963). A study on the killing by light of photosensitized cells of Halobacterium salinarium. Arch Mikrobiol 46 : 19-28.

Fasano, E., Serini, S., Mondella, N., Trombino, S., Celleno, L., Lanza, P., Cittadini, A., and Calviello, G. (2014). Antioxidant and anti-Inflammatory effects of selected natural compounds contained in a dietary supplement on two human immortalized keratinocyte lines.Biomed Res Int 2014 : 1-11.

Fidan, O., and Zhan, J. (2019). Discovery and engineering of an endophytic Pseudomonas strain from Taxus chinensis for efficient production of zeaxanthin diglucoside. J Biol Eng13: 66.

Figueroa-Bossi, N., Lemire, S., Maloriol, D., Balbontín, R., Casadesús, J., and Bossi, L. (2006). Loss of Hfq activates the sigmaE-dependent envelope stress response in Salmonella enterica. Mol Microbiol 62 : 838-852.

Fröhlich, K. S., and Vogel, J. (2009). Activation of gene expression by small RNA. Curr Opin Microbiol 12 : 674-682.

Fuqua, C., Winans, S. C., and Greenberg, E. P. (1996). Census and consensus in bacterial ecosystems: the LuxR-LuxI family of quorum-sensing transcriptional regulators. Annu Rev Microbiol50 : 727-751.

Gaida, S. M., Al-Hinai, M. A., Indurthi, D. C., Nicolaou, S. A., and Papoutsakis, E. T. (2013). Synthetic tolerance: three noncoding small RNAs, DsrA, ArcZ and RprA, acting supra-additively against acid stress.Nucleic Acids Res 41 : 8726-8737. 
Gao, M., Tang, M., Guerich, L., Salas-Gonzalez, I., and Teplitski, M. (2015). Modulation of Sinorhizobium meliloti quorum sensing by Hfq-mediated post-transcriptional regulation of ExpR. Environ Microbiol Rep 7 : $148-154$.

Gish, W., and States, D. J. (1993). Identification of protein coding regions by database similarity search. Nat Genet 3 : 266-272.

Gottesman, S., McCullen, C. A., Guillier, M., Vanderpool, C. K., Majdalani, N., Benhammou, J, Thompson, K., FitzGerald, P., Sowa, N., and FitzGerald, D. (2006). Small RNA regulators and the bacterial response to stress. Cold Spring Harb Symp Quant Biol 71 : 1-11.

Guerinot, M. L. (2000). The green revolution strikes gold.Science 287 : 241-243.

Higuchi, R., Krummel B., and Saiki, R. K. (1988). A general method of in vitro preparation and specific mutagenesis of DNA fragments: study of protein and DNA interactions. Nucleic Acids Res15 : 7351-7367.

Ho, S. N., Hunt, H. D., Horton, R. M., Pullen, J. K., and Pease, L.R. (1989). Site-directed mutagenesis by overlap extension using the polymerase chain reaction. Gene 77 : 51-59.

Horton, R. M., Cai, Z., Ho, S. N., and Pease, L. R. (1995). Gene splicing by overlap extension: tailor-made genes using the polymerase chain reaction. BioTechniques $\mathbf{5 4}: 528-535$.

Horton, R. M., Hunt, H. D., Ho, S. N., Pullen, J. K., and Pease, L. R. (1989). Engineering hybrid genes without the use of restriction enzymes: gene splicing by overlap extension. Gene 77 : 61-68.

Hundle, B., Alberti, M., Nievelstein, V., Beyer, P., Kleinig, H., Armstrong, G. A., Burke, D. H., and Hearst, J. E. (1994). Functional assignment of Erwinia herbicola Eho10 carotenoid genes expressed in Escherichia coli . Mol Gen Genet 245 : 406-416.

Hussain, H., and Chong, N. (2016). Combined overlap extension PCR method for improved site directed mutagenesis. Biomed Res Int 2016 : 8041532.

Hwang, W., Arluison, V., and Hohng, S. (2011). Dynamic competition of DsrA and rpoS fragments for the proximal binding site of Hfq as a means for efficient annealing. Nucleic Acids Res 39 : 5131-5139.

llis, K., Faloona, F., Scharf, S., Saiki, R., Horn, G., and Erlich, H. (1986). Specific enzymatic amplification of DNA in vitro : the polymerase chain reaction. Cold Spr Harb Symp Quant BioiL1 : 263-273.

Kalogeraki, V. S., and Winans, S. C. (1997). Suicide plasmids containing promoterless reporter genes can simultaneously disrupt and create fusions to target genes of diverse bacteria. Gene 188 : 69-75.

Kang, B. (2017). Hfq regulates Pathogenicity in Pantoea ananatis . Master of Science Thesis, Gyeongsang National University .

Kay, E., Humair, B., Dénervaud, V., Riedel, K., Spahr, S., Eberl, L., Valverde, C., and Haas, D. (2006). Two GacA-dependent small RNAs modulate the quorum-sensing response in Pseudomonas aeruginosa.$J$ Bacteriol 188 : 6026-6033.

Keen, N. T., Tamaki, S., Kobayashi, D., and Trollinger, D. (1988). Improved broad-host-range plasmids for DNA cloning in gram-negative bacteria. Gene 70 : 191-197.

Khan, S. R., Gaines, J., Roop, R. M. 2nd, and Farrand, S. K. (2008). Broad-host-range expression vectors with tightly regulated promoters and their use to examine the influence of TraR and TraM expression on $\mathrm{Ti}$ plasmid quorum sensing. Appl Environ Microbiol 74 : 5053-5062.

Kim, J., and Choi, O. (2012). An outbreak of onion center rot caused by Pantoea ananatis in Korea. Plant Dis 96 : 1576.

Kim, J., Heindl, J. E., Fuqua, C. (2013). Coordination of division and development influences complex multicellular behavior inAgrobacterium tumefaciens. PloS ONE 8 : e56682. 
Kim, J., Kim, J.-G., Kang, Y., Jang, J. Y., Jog, G. J., Lim, J. Y., Kim, S., Suga, H., Nagamatsu, T., and Hwang, I. (2004). Quorum sensing and the LysR-type transcriptional activator ToxR regulate toxoflavin biosynthesis and transport in Burkholderia glumae. Mol Microbiol 54 : 921-934.

Kirti, K., Amita, S., Priti, S., Kumar, A. M., and Jyoti, S. (2014). Colorful world of microbes: Carotenoids and their applications.Advan Biol $2014: 13$.

Kovach, M. E., Elzer, P. H., Hill, D. S., Robertson, G. T., Farris, M. A., Martin Roop II, R., and Peterson, K. M. (1995). Four new derivatives of the broad-host-range cloning vector pBBR1MCS, carrying different antibiotic-resistance cassettes. Gene 166 : 175-176.

Kunisawa, R., and Stanier, R. Y. (1958). Studies on the role of carotenoids pigments in a chemoheterotrophic bacterium, Corynebacterium poinsettiae . Arch Mikrobiol 31 : 146-156.

Lassak, J., Henche, A.L., Binnenkade, L., and Thormann, K. M. (2010). ArcS, the cognate sensor kinase in an atypical Arc system ofShewanella oneidensis MR-1. Appl Environ Microbiol76 : 3263-3274.

Lee, P. C., Momen, A. Z., Mijts, B. N., and Schmidt-Dannert, C. (2003). Biosynthesis of structurally novel carotenoids in Escherichia coli . Chem Biol 10 : 453-462.

Lee, Y. S. (2015). Quorum sensing and RpoS regulate carotenoid biosynthesis of Pantoea ananatis PA13. Master of Science Thesis, Gyeongsang National University .

Lenz, D. H., Mok, K. C., Lilley, B. N., Kulkarni, R. V., Wingreen, N. S., and Bassler, B. L. (2004). The small RNA chaperone Hfq and multiple small RNAs control quorum sensing in Vibrio harveyi and Vibrio cholerae . Cell $118: 69-82$.

Lorenz, C., Gesell, T., Zimmermann, B., Schoeberl, U., Bilusic, I., Rajkowitsch, L., Waldsich, C., von Haeseler, A., and Schroeder, R. (2010). Genomic SELEX for Hfq-binding RNAs identifies genomic aptamers predominantly in antisense transcripts. Nucleic Acids Res38 : 3794-3808.

Lorquin, J., Molouba, F., and Dreyfus, B.L. (1997). Identification of the carotenoid pigment canthaxanthin from photosyntheticBradyrhizobium strains. Appl Environ Microbiol63 : 1151-1154.

Lu, Q., Bu, Y.-F., and Liu, J. -Z. (2017). Metabolic engineering ofEscherichia coli for producing astaxanthin as the predominant carotenoid. Marine Drugs 15 : 296.

Lutnaes, B. F., Strand, Å., Pétursdóttir, S. K., and Liaaen-Jensen, S. (2004). Carotenoids of thermophilic bacteria-Rhodothermus marinus from submarine Icelandic hot springs. Biocheml System Ecol 32 : 455-468.

Mandin, P., and Gottesman, S. (2010). Integrating anaerobic/aerobic sensing and the general stress response through the ArcZ small RNA.EMBO J 29 : 3094-3107.

Majdalani, N., Vanderpool, C. K., and Gottesman, S. (2005). Bacterial small RNA regulators. Crit Rev Biochem Mol Biol 40 : 93-113.

Mathews, M. M., and Sistrom, W. R. (1959). Function of carotenoid pigments in non-photosynthetic bacteria. Nature 184 : 1892-1896.

Mathews, M. M., and Sistrom, W. R. (1960). The function of carotenoid pigments of Sarcina lutea . Arch Microbiol 35 : 139-146.

Merritt, P. M., Danhorn, T., and Fuqua, C. (2007). Motility and chemotaxis in Agrobacterium tumefaciens surface attachment and biofilm formation. J Bacteriol 189 : 8005-8014.

Mijts, B. N., and Schmidt-Dannert, C. (2003). Engineering of secondary metabolite pathways. Curr Opin Biotechnol 14 : 597-602.

Minogue, T. D., Carlier, A. L., Koutsoudis, M. D., and Beck von Bodman, S. B. (2005). The cell densitydependent expression of stewartan exopolysaccharide in Pantoea stewartii ssp. stewartii is a function of 
EsaR-mediated repression of the rcsA gene. Mol Microbiol 56 : 189-203.

Misawa, N., Satomi, Y., Kondo, K., Yokoyama, A., Kajiwara, S., Saito, T., Ohtani, T., and Miki, W. (1995). Structure and functional analysis of a marine bacterial carotenoid biosynthesis gene cluster and astaxanthin biosynthetic pathway proposed at the gene level. J Bacteriol 177 : 6575-6584.

Mohammadi, M., Burbank, L., and Roper, C. (2012). The biological role of pigment production for the bacterial phytopathogen, Pantoea stewartii subsp. stewartii . Appl Environ Microbiol78 : 6859-6865.

Moran, N. A., and Jarvik, T. (2010). Lateral transfer of genes from fungi underlies carotenoid production in aphids. Science 328 : $624-627$.

Morohoshi, T., Nakamura, Y., Yamazaki, G., Ishida, A., Kato, N., and Ikeda, T. (2007). The plant pathogen Pantoea ananatis produces $N$-acylhomoserine lactone and causes center rot disease of onion by quorum sensing. J Bacteriol 189 : 8333-8338.

Mostofian, B., Johnson, Q. R., Smith, J. C., and Cheng, X. (2020). Carotenoids promote lateral packing and condensation of lipid membranes.Phys Chem Chem Phys 7 : 12281-12293.

Muffler, A., Fischer, D., and Hengge-Aronis, R. (1996). The RNA-binding protein HF-I, known as a host factor for phage $\mathrm{Q} \beta$ RNA replication, is essential-for rpoS translation in Escherichia coli .Genes Dev 10 : $1143-1151$.

Oren. A. 2009. Microbial diversity and microbial abundance in salt-saturated brines: Why are the waters of hypersaline lakes red? Natural Resources and Environmental Issues 15 : 49.

Paliwal, C., Mitra, M., Bhayani, K., Bharadwaj, S. V., Ghosh, T., Dubey, S., and Mishra, S. (2017). Abiotic stresses as tools for metabolites in microalgae. Bioresour Technol 244 : 1216-1226.

Papenfort, K., Said, N., Welsink, T., Lucchini, S., Hinton, J. C. D., and Vogel, J. (2009). Specific and pleiotropic patterns of mRNA regulation by ArcZ, a conserved, Hfq-dependent small RNA. Mol Microbiol $74: 139-158$.

Platt, T. G., and Fuqua, C. (2010). What's in a name? The semantics of quorum sensing. Trends Microbiol $18: 383-387$.

Raju, R., Goldberg, A., and Rubin, E. (2012). Bacterial proteolytic complexes as therapeutic targets. Nat Rev Drug Discov11 : 777-789.

Ram, S., Mitra, M., Shah, F., Tirkey, S. R., and Mishra, S. (2020). Bacteria as an alternate biofactory for carotenoid production: A review of its applications, opportunities and challenges. J Func Foods67 : 103867.

Ram, S., Paliwal, C., and Mishra, S. (2019). Growth medium and nitrogen stress sparked biochemical and carotenogenic alterations inScenedesmus sp. CCNM 1028. Bioresour Technol Rep7 : 100194.

Repoila, F., Majdalani, N., and Gottesman, S. (2003). Small non-coding RNAs, co-ordinators of adaptation processes in Escherichia coli : The RpoS paradigm. Mol Microbiol 48 : 855-861.

Sajilata, M., Singhal, R., and Kamat, M. (2008). The carotenoid pigment zeaxanthin - A review. Compr Rev Food Sci Food Saf $7: 29-49$.

Sambrook, J., and Russell, D. W. (2001). Molecular Cloning: A Laboratory Manual. Cold Spring Harbor, NY: Cold Spring Harbor Laboratory Press.

Sandmann, G., Albrecht, M., Schnurr, G., Knorzer, O., and Boger, P. (1999). The biotechnological potential and design of novel carotenoids by gene combination in Escherichia coli. Trends Biotechnol17 : 233-237.

Sandmann, G., Woods, W. S., and Tuveson, R. W. (1990). Identification of carotenoids in Erwinia herbicola and in a transformedEscherichia coli strain. FEMS Microbiol Lett 71 : 77-82. 
Schachterle, J. K., and Sundin, G. W. (2019). The leucine-responsive regulatory protein participates in virulence regulation downstream of small RNA ArcZ in Erwinia amylovora . mBio . 10 : e00757-19.

Sedkova, N., Tao, L., Rouvie're, P. E., and Cheng, Q. (2005). Diversity of carotenoid synthesis gene clusters from environmentalEnterobacteriaceae strains. Appl Environ Microbiol71 : 8141-8146.

Shin, G. Y., Schachterle, J. K., Shyntum, D. Y., Moleleki, L. N., Coutinho, T. A., and Sundin, G. W. (2019). Functional characterization of a global virulence regulator Hfq and identification of Hfq-dependent sRNAs in the plant pathogen Pantoea ananatis. Front Microbiol 10 : 2075.

Sittka, A., Pfeiffer, V., Tedin, K., and Vogel, J. (2007). The RNA chaperone Hfq is essential for the virulence of Salmonella typhimurium . Mol Microbiol 63 : 193-217.

Song, G. H., Kim, S. H., Choi, B. H., Han, S. J., and Lee, P. C. (2013). Heterologous carotenoid-biosynthetic enzymes: functional complementation and effects on carotenoid profiles in Escherichia coli. Appl Environ Microbiol 79 : 610-618.

Soper, T., Mandin, P., Majdalani, N., Gottesman, S., and Woodson, S. A. (2010). Positive regulation by small RNAs and the role of Hfq.Proc Natl Acad Sci U S A 107 : 9602-9607.

Stanier, R. Y. (1959). Formation and function of the photosynthetic pigment system in purple bacteria. The photochemical apparatus: Its structure and function. Brookh Symp Biol 11 : 43-53.

Storz, G., Altuvia, S., and Wassarman, K. M. (2005). An abundance of RNA regulators. Annu Rev Biochem 74: 199-217.

Storz, G., Opdyke, A. J., and Zhang, A. (2004). Controlling mRNA stability and translation with small, noncoding RNAs. Curr Opin Microbiol 7 : 140-144.

Tian, B., and Hua. Y. (2010). Carotenoid biosynthesis in extremophilicDeinococcus-Thermus bacteria. Trend Microbiol 18 : 512-520.

Vila, E., Hornero-Méndez, D., Azziz, G., Lareo, C., and Saravia, V. (2019). Carotenoids from heterotrophic bacteria isolated from Fildes Peninsula, King George Island, Antarctica. Biotechnol Rep21 : e00306.

Virtamo, J., Taylor, P. R., Kontto, J., Männistö, S., Utriainen, M., Weinstein, S. J., Huttenen, J., and Albanes, D. (2014). Effects of $\alpha$-tocopherol and $\beta$-carotene supplementation on cancer incidence and mortality: 18-year post-intervention follow-up of the alpha-tocopherol, beta-carotene cancer prevention (ATBC) study. Int J Cancer 135 : 178-185.

Vogel, J., and Wagner, E. G. H. (2007). Target identification of small noncoding RNAs in bacteria. Curr Opin Microbiol 10 : 262-270.

Wang, C., Pu, T., Lou, W., Wang, Y., Gao, Z., Hu, B., and Fan, J. (2018). Hfq, a RNA chaperone, contributes to virulence by regulating plant cell wall-degrading enzyme production, type VI secretion system expression, bacterial competition, and suppressing host defense response in Pectobacterium carotovorum . Mol Plant Microbe Interact31 : 1166-1178.

Warrens, A. N., Jones, M. D., and Lechler, R. I. (1997). Splicing by overlap extension by PCR using asymmetric amplification: an improved technique for the generation of hybrid proteins of immunological interest. Gene 186 : 29-35.

Waters, C. M., and Bassler, B. L. (2005). Quorum sensing: cell-to-cell communication in bacteria. Annu Rev Cell Dev Biol 21 : 319-346.

Waters, L.S., and Storz, G. (2009). Regulatory RNAs in bacteria.Cell 136 : 615-628.

Weller-Stuart, T., De Maayer, P., and Coutinho, T. (2017). Pantoea ananatis : genomic insights into a versatile pathogen. Mol Plant Pathol 18 : 1191-1198. 
Xiao, Y.-H., Yin, M.-H., Hou, L., Luo, M., and Pei, Y. (2007). Asymmetric overlap extension PCR method bypassing intermediate purification and the amplification of wild-type template in site-directed mutagenesis. Biotechnol Lett 29 : 925-930.

Xu, J., Kim, J., Benjamin, J., Koestler, B. J., Choi, J.-H., Christopher M. Waters, C. M., and Fuqua, C. (2013). Genetic analysis of Agrobacterium tumefaciens unipolar polysaccharide production reveals complex integrated control of the motile-to-sessile switch. Mol Microbiol 89 : 929-948.

Zeng, F., Zhang, Y., Zhang, Z., Malik, A. A., and Lin, Y. (2017). Multiple-site fragment deletion, insertion and substitution mutagenesis by modified overlap extension PCR. Biotechnol Biotec Eq 31 : 339-348.

Zeng, Q., McNally, R. R., and Sundin, G. W. (2013). Global small RNA chaperone Hfq and regulatory small RNAs are important virulence regulators in Erwinia amylovora. J Bacteriol 195 : 1706-1717.

Zeng, Q., and Sundin, G. W. (2014). Genome-wide identification of Hfq-regulated small RNAs in the fire blight pathogen Erwinia amylovora discovered small RNAs with virulence regulatory function. $B M C$ Genomics 15 : 414.

\section{FIGURE LEGENDS}

Fig. 1. Genetic map and putative pathway responsible for carotenoid biosynthesis by $P$. ananatis PA13 (CP003086) and $P$. agglomerans Eho10 (M87280). (A) The carotenoid gene cluster of $P$. ananatis consisted of $c r t E-X-Y-I-B$ and $Z$; and that for $P$. agglomerans of $\operatorname{crt} E-i d i-\operatorname{crt} X-Y-I-B$ and $Z$. Gene numbers were shown on the carotenoid gene map. (B) The putative carotenoid biosynthetic pathway of $P$ . ananatisinferred according to the pathway of Pantoea species (Misawaet al ., 1995) and plants (Guerinot, 2000). The involved enzymes include isopenthyl diphosphate (IPP) isomerase encoded by $i d i$,geranylgeranyl diphosphate (GGPP) synthetase by $\operatorname{crtE}$, phytoene synthase by $\operatorname{crt} B$, phytoene desaturase by $\operatorname{crtI}$, lycopene $\beta$-cyclase by $\operatorname{crt} Y$, $\beta$-carotene hydroxylase by $\operatorname{crt} Z$, and zeaxanthin glucosyl transferase by $\operatorname{crt} X$.

Fig. 2. Confirmation of transcriptional units in the carotenoid gene cluster of $P$. ananatis by RT-PCR. RT-PCR products were confirmed by Southern hybridisation. Black arrows indicate the extension and transcription directions of the $\operatorname{crtEXYIB}$ operon and $\operatorname{crt} Z$ gene. An arrow below the open arrows represents the product of RT reactions. The short thick bars below the RT arrow indicate the PCR products from the corresponding RT reactions. The expected sizes of the PCR products are indicated below the labels. Agarose gel analysis (upper panel) and Southern analysis (lower panel) of the RT-PCR products of the crtEXYIB operon and $c r t Z$ gene. Southern hybridisation was performed using pCOK128 as a probe. Lanes 1-3, 4-6, 7-9, 10-12, and 13-15 correspond to the products of PCR1, PCR2, PCR3, PCR4, and PCR5, respectively. Lanes 1, 4, 7, 10, and 13: PCR products from the DNA template as positive controls; lanes 2, 5, 8, 11, and 14: PCR products from the RNA template as negative controls; and lanes 3, 6, 9, 12, and 15: RT-PCR products.

Fig. 3. Production of phytoene, lycopene, and $\beta$-carotene inE. coli. HPLC analysis of phytoene (A), lycopene (B), and $\beta$-carotene (C) production. a, E. coliDH5 $\alpha / \mathrm{pYS71}(\mathrm{pBBR} 1 \mathrm{MCS} 5:$ : crtE-B) producing phytoene (retention time $2 \mathrm{~min}, 280 \mathrm{~nm}$ ); b, E. coliDH5 $\alpha /$ pYS69(pBBR1MCS5::crtE-B-I) producing lycopene (retention time $11 \mathrm{~min}, 470 \mathrm{~nm}$ ); and c, E. coliDH5 $\alpha /$ pYS76(pBBR1MCS5::crtE-B-I-Y) producing $\beta$-carotene (retention time $14.8 \mathrm{~min}, 450 \mathrm{~nm}$ ). HPLC analysis confirmed that the E. coli strains harbouring pYS71, pYS69, and pYS76 produced phytoene, lycopene, and $\beta$-carotene, respectively. (D), Colour change of harvested E. coli cells harbouring pYS71, pYS69, or pYS76. The harvested cells showed colourless phytoene, magenta lycopene, or orange $\beta$-carotene. PS, LS, and CS indicate the phytoene, lycopene, and $\beta$-carotene standards, respectively.Fig. 4. Carotenoids confer toxoflavin tolerance to P.ananatis. (A) Construction of the crtE::pCOK184 mutant and complementation plasmid pCOK218. - or + indicates negative or positive carotenoid production, respectively. (B) Toxoflavin tolerance of $P$. ananatis. The wild-type and $c r t E:$ :pCOK184 mutant carrying pCOK218 exhibited greater toxoflavin tolerance than the $r$ tE mutant; however, the $\operatorname{crtE}:$ :pCOK184 mutant was more sensitive than the wild-type to toxoflavin at $20 \mu \mathrm{g} \mathrm{mL}^{-1}$. Pantoea ananatis PA13 is sensitive to toxoflavin concentrations $>20 \mu \mathrm{g} \mathrm{mL}^{-1}$. 
Fig. 5. $\mathrm{Hfq}^{\mathrm{ArcZ}}$ - RpoS ClpXP regulatory networks. (A) An illustration showing the Hfq ${ }^{\mathrm{ArcZ}}$ - RpoS ClpXP regulatory networks based on $E$. coli (Rajuet al ., 2012). RpoS is regulated positively by Hfq and its cognate sRNA ArcZ, and negatively by ClpXP. RpoS-dependent carotenoid production in $P$. agglomerans (formerly Erwinia herbicola) was reported previously (Becker-Hapaka et al ., 1997). (B) Carotenoid production in the wild-type (W), [?] rpoS,[?] hfq, [?] $\operatorname{arcZ}$, [?] $\operatorname{clpP}$, and complementation (+) strains. Values are means \pm standard deviation (SD) of three independent experiments. ${ }^{*} \mathrm{p}<0.05 ;{ }^{* *} \mathrm{p}<0.01{ }^{* * *} \mathrm{p}<0.001$ vs. wild-type.

Fig. 6. EanR negatively regulates carotenoid productionvia inhibition of rpoS . (A) QS signal production of the wild-type and [?] eanI, [?] ean $R$, and [?] eanI- $R$ mutants as well as the [?] eanI- $R$ mutant carrying pCOK199 on $C$.violaceum CV026 biosensor-embedded plates. (B) Carotenoid production of the wild-type and [?] eanI, [?] eanR, and [?] eanI-R mutants as well as the [?] eanI-R mutant carrying pCOK199. (C) Quantification of carotenoid production of the PA13 derivatives. Carotenoid production was identical to that shown in (B). Values are means +- standard deviation (SD) of three independent experiments. ${ }^{* * *} \mathrm{p}<0.001$ vs. wild-type. (D) $\beta$-Galactosidase activity reporting rpoS expression. rpoS expression was induced in the absence of EanR and decreased in the absence of EanI, indicating that EanR negatively regulates rpoS expression and QS signals de-repress EanR. Values are means \pm standard deviation (SD) of three independent experiments. ${ }^{* * *}$ p $<0.001$ vs. PA13L. (E) Genetic map of rpoS locus and putative lux box. Inverted repeat sequences are shown in bold.

Fig. 7. Hfq regulates the expression of eanI QS signal synthase. (A) Characterisation and quantification of AHL signals in wild-type (W), [?] hfq mutant (-), and complementation (+; pCOK335) strains of $P$. ananatis PA13. The culture supernatants of the PA13 derivatives were extracted with ethyl acetate at $\mathrm{OD}_{600}$ values of $0.9,1.5$ and 1.8. Ethyl acetate extracts were applied to $\mathrm{C}_{18}$ reversed-phase thin layer chromatography (TLC) plates. AHL signals were visualised with the $C$. violaceum CV026 biosensor, and synthetic C6-HSL and 3-oxo-C6-HSL were used as AHL standards. (B) 3-oxo-C6AHL signal production of the wild-type (W), [?] $h f q$ mutant (-), and complementation strain carrying pCOK335 (+; pLAFR3::hfq ). Relative percentage to the wild-type at $\mathrm{OD}_{600}$ 1.8. The purple area of the 3-oxo-C6AHL signals from TLC was calculated using the ImageJ program. Values are means +- standard deviation (SD) of three independent experiments. ${ }^{*} \mathrm{p}<0.05 ;{ }^{* *} \mathrm{p}<0.01 ;{ }^{* * *} \mathrm{p}<0.001$ vs. wild-type. (C) $\beta$-Galactosidase activity reporting eanI expression in PA13L, [?] hfq mutant (-), and complementation strain (+; pLAFR3::hfq). Values are means \pm standard deviation (SD) of three independent experiments. ${ }^{* * *} \mathrm{p}<0.01$ vs. PA13L.

Fig. 8. Proposed model of carotenoid production for the previously reported regulatory network Hfq ${ }^{\text {ArcZ }}$ RpoS ClpXP and that identified here in which Hfq-controlled quorum signalling de-represses EanR to activate RpoS, thereby initiating carotenoid production. Carotenoid production confers tolerance to toxoflavin and UV radiation.

\section{Supporting information figure legends}

Supplementary Fig. S1. Recombinant plasmids for rearrangement of the carotenoid genes responsible for synthesising phytoene, lycopene, and $\beta$-carotene. The SOE by PCR products were first cloned into pGEMT Easy, digested with Xhol and Sacl, and ligated into the corresponding position of pBBR1MCS5. Open triangles indicate the lac $Z$ RBS. The SacI site, which is dotted and parenthesised, was from the pGEM-T Easy vector.

Supplementary Fig. S2. Confirmation of transcriptional units in the reassembled $\operatorname{crt} E-B$, crt $E-B-I$ , and $\operatorname{crt} E-B-I-Y$ operons by RT-PCR. RT-PCR products were confirmed by Southern hybridisation. Black arrows indicate the extension and transcription directions of the $\operatorname{crt} E-B, \operatorname{crt} E-B-I$, and $\operatorname{crt} E-B$ $-I-Y$ operons on plasmids pYS71 (A), pYS69 (B), and pYS76 (C), respectively. Arrows below the open arrows represent the products of RT reactions. The short thick bars below the RT arrow indicate the PCR products from the corresponding RT reactions. The expected sizes of the PCR products are indicated below the labels. Agarose gel analysis (upper panel) and Southern analysis (lower panel) of the RT-PCR products of the $\operatorname{crt} E-B, \operatorname{crt} E-B-I$, and $\operatorname{crt} E-B-I-Y$ operons. Southern hybridisation was performed using the $\operatorname{crt} E-B-I-Y$ operon region $(2.2,3$, and $5 \mathrm{~kb}$ XhoI-SacI fragments of pYS71, pYS69, and pYS76, 
respectively) as probes. Lanes 1-3, 4-6, and 7-9 correspond to the products of PCR1, PCR2, and PCR3, respectively. Lanes 1, 4, and 7: PCR products from the DNA template as positive controls; lanes 2, 5, and 8: PCR products from the RNA template as negative controls; and lanes 3, 6, and 9: RT-PCR products.

Supplementary Fig. S3. Carotenoid production confers UV radiation tolerance to $P$. ananatis. The wild-type and $\operatorname{crtE}:$ :pCOK184 mutant harbouring pCOK218 exhibited greater UV radiation tolerance than the $\operatorname{crtE}$ mutant at wavelengths of 320-400 nm for $20 \mathrm{~s}$; however, the $\operatorname{crtE}:$ :pCOK184 mutant showed lower UV radiation tolerance than the wild-type.

Supplementary Fig. S4. QS system of $P$. ananatisPA13. (A) Genetic map of the eanR and eanI loci of the QS system in $P$. ananatis PA13 and mutant generation. The putative lux box is upstream of eanR, for comparison, theesaR lux box of $P$. stewartii subsp.stewartii and lux box of Vibrio fischeri are presented. Campbell insertion and non-polar deletion mutants were generated to determine if eanR regulates the expression of eanI ; a) PA13L, non-polar deletion of $l a c Z Y$ genes from wild-type PA13 used in the $\beta$-galactosidase assays as the wild-type; b)eanI ::pCOK153 (pVIK112 carrying truncated eanI at both ends); c) [?] eanI , non-polar deletion of eanI ; d) [?] eanR, non-polar deletion of eanR ; and e) [?] eanR eanI ::pCOK153. (B) Characterisation and quantification of AHL signals of the PA13 derivatives: (a) PA13L; (b) eanI ::pCOK153; (c) [?] eanI mutant; (d) [?] eanR mutant; and (e) [?] eanR eanI ::pCOK153 mutant. Ethyl acetate extracts were applied to $\mathrm{C}_{18}$ reversed-phase thin layer chromatography (TLC) plates. AHL signals were visualised with the $C$. violaceum CV026 biosensor, and synthetic C6-HSL and 3-oxo-C6-HSL were used as AHL standards (s). (C) $\beta$-Galactosidase activity reporting eanI expression.

Supplementary Fig. S5. Strategy for generating recombinant carotenoid genes responsible for synthesising phytoene, lycopene, and $\beta$-carotene. PCR products with their overlapping regions aligned and the final rearrangement products are shown. The $\mathrm{SOE}$ by $\mathrm{PCR}$ products $\mathrm{AD}, \mathrm{AF}$, and $\mathrm{AH}$ are shown. In each case, the overlapping region between the primers, and the priming region in which each primer recognises its template, was designed to have the ribosome binding sequence (RBS) of each gene. The XhoI recognition sequence and lacZ RBS were introduced at the beginning of SOE-AB products. Dotted arrows indicate the rearrangements of carotenoid genes.

The English in this document has been checked by at least two professional editors, both native speakers of English. For a certificate, please see:

http://www.textcheck.com/certificate/LUJkAo 
(A)

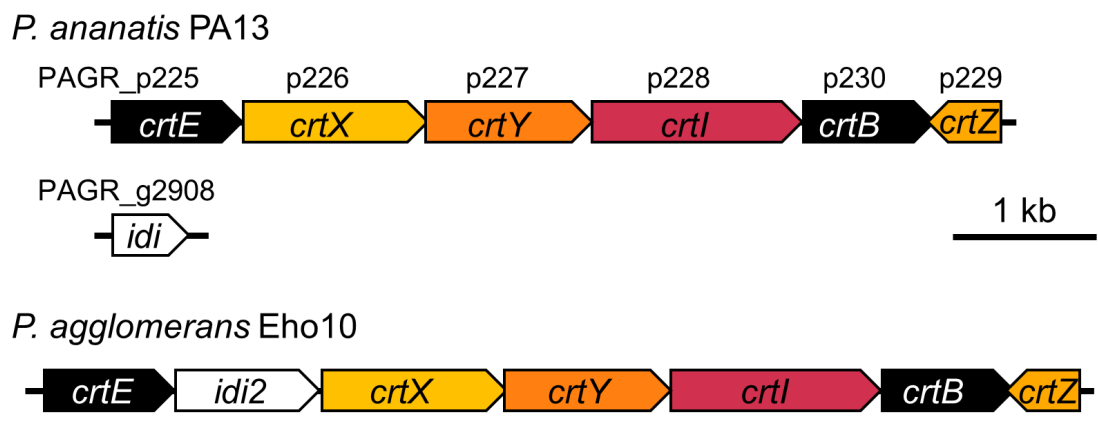

(B)

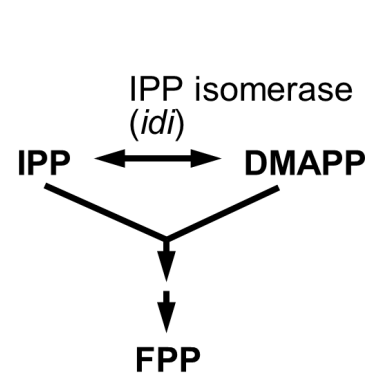

$$
\begin{aligned}
& \text { FPP } \\
& \begin{array}{l}
\text { GGPP synthetase } \\
\text { (crtE) }
\end{array} \\
& \text { GGPP } \\
& \downarrow \begin{array}{l}
\text { Phytoene synthase } \\
(\text { crtB })
\end{array}
\end{aligned}
$$
Zeaxanthin diglucoside

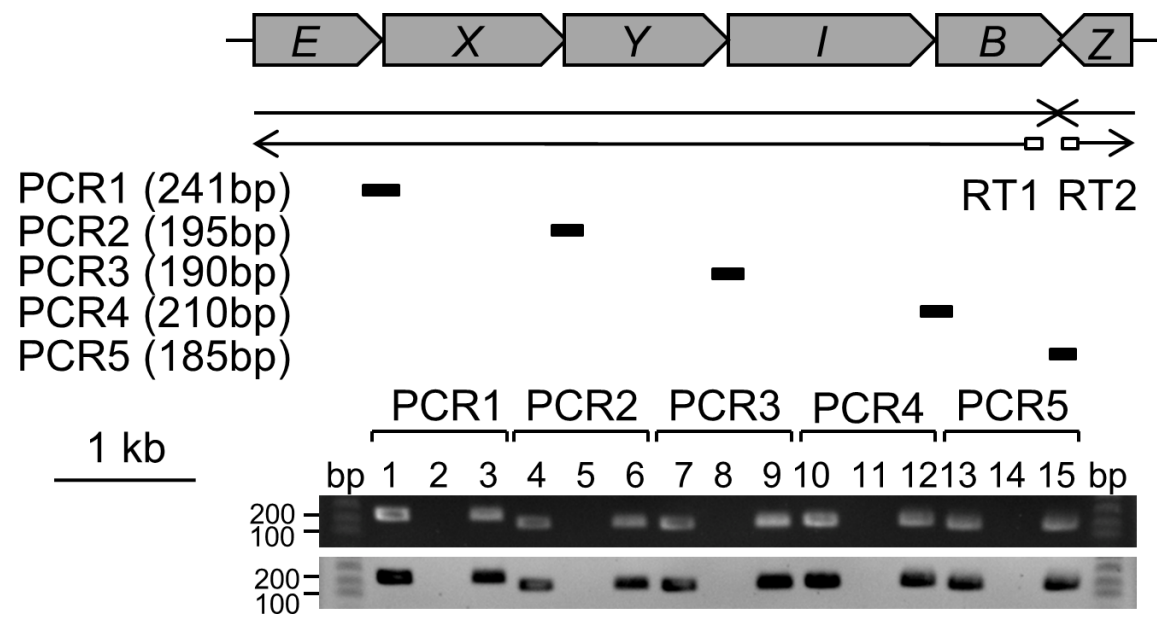


(A) $2500 \mathrm{mV}$

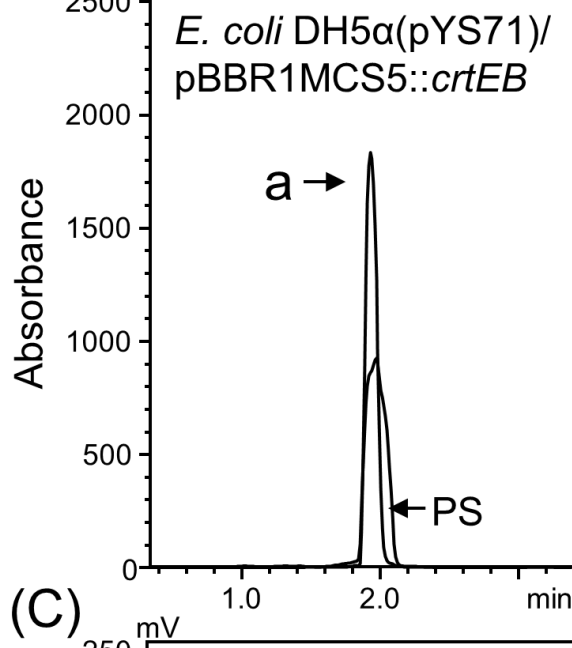

(C)

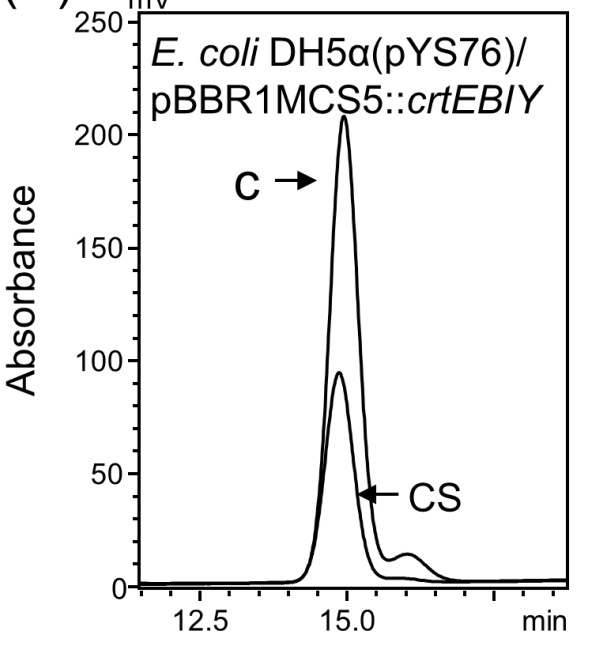

(B)
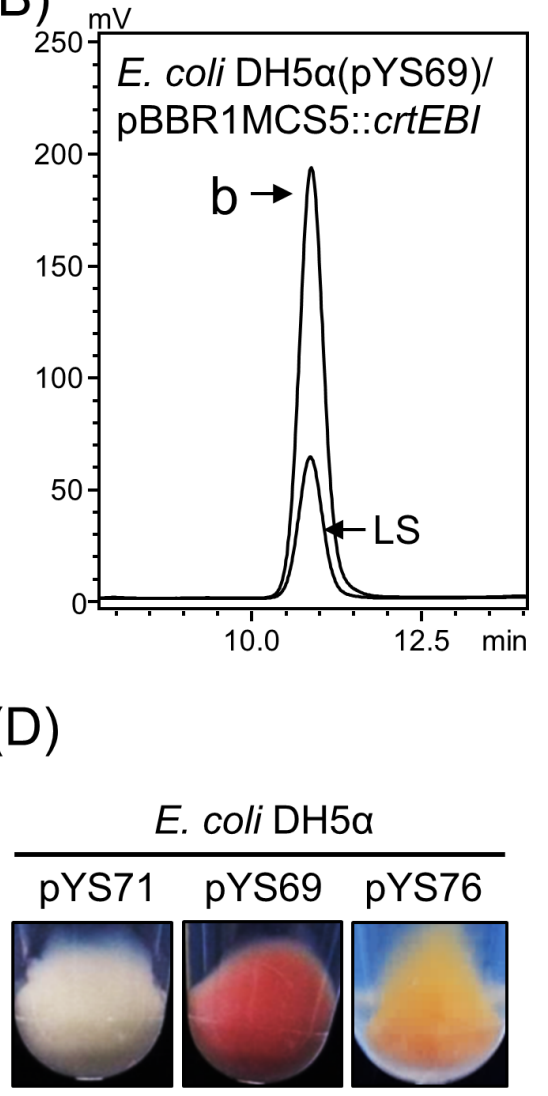
(A)

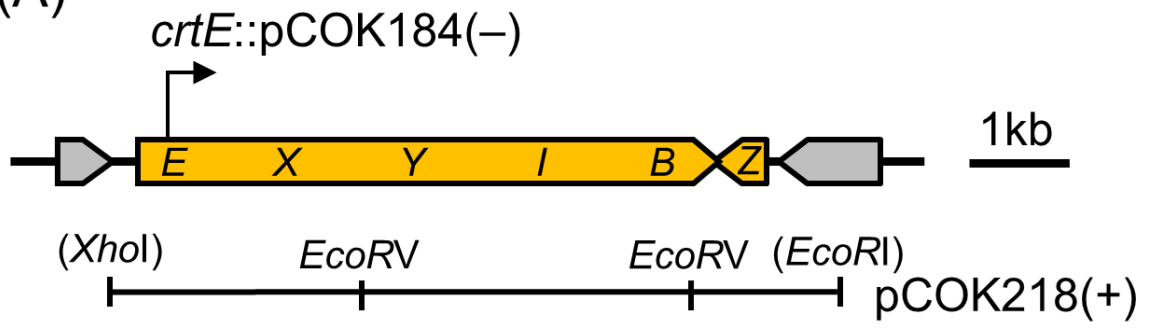

(B)

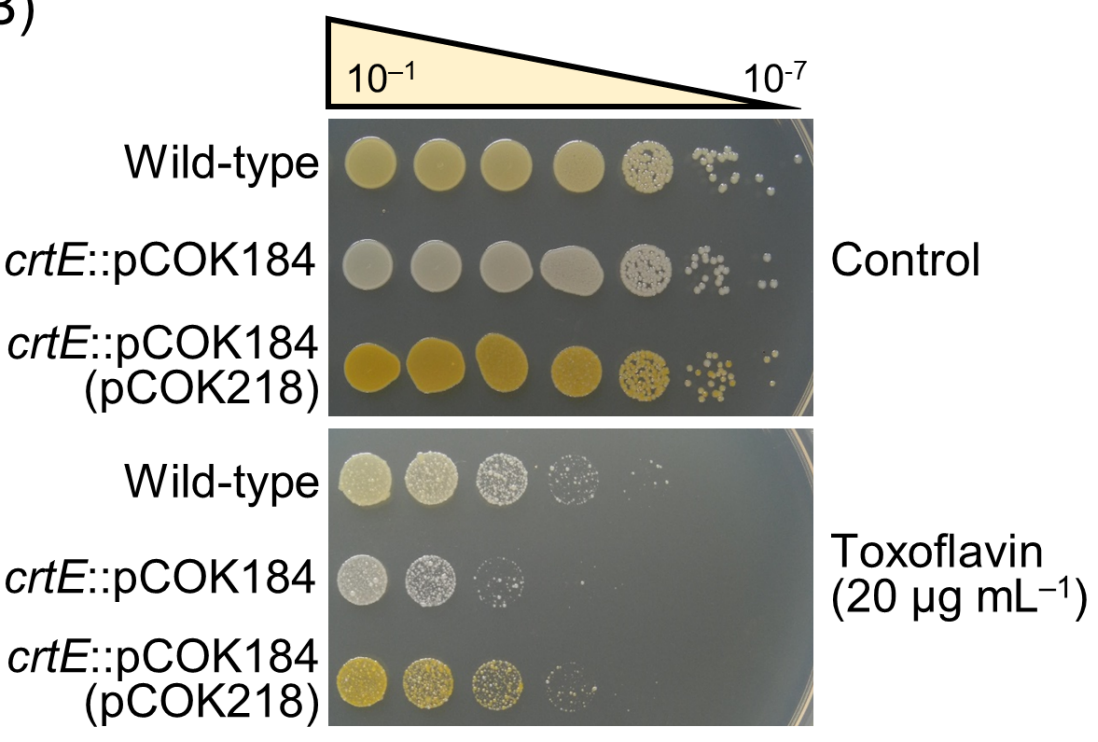


(A)

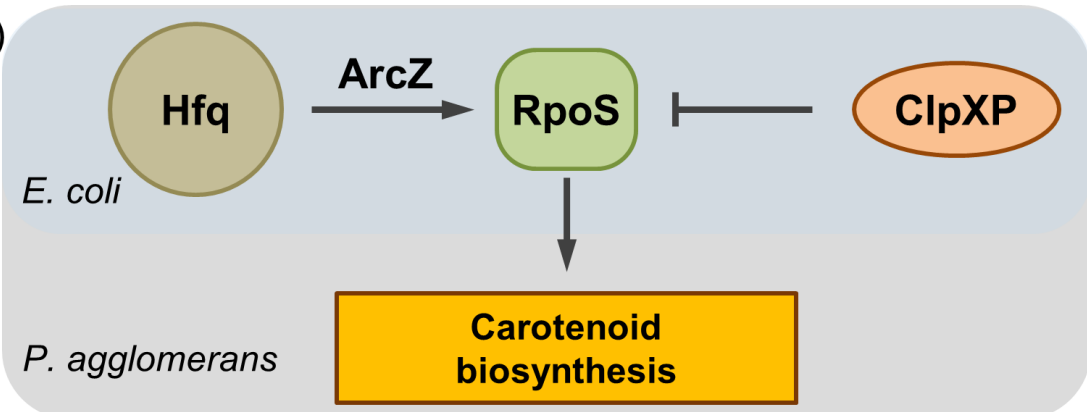

(B) Wild-type $\Delta r p o s \quad \Delta r p o s$

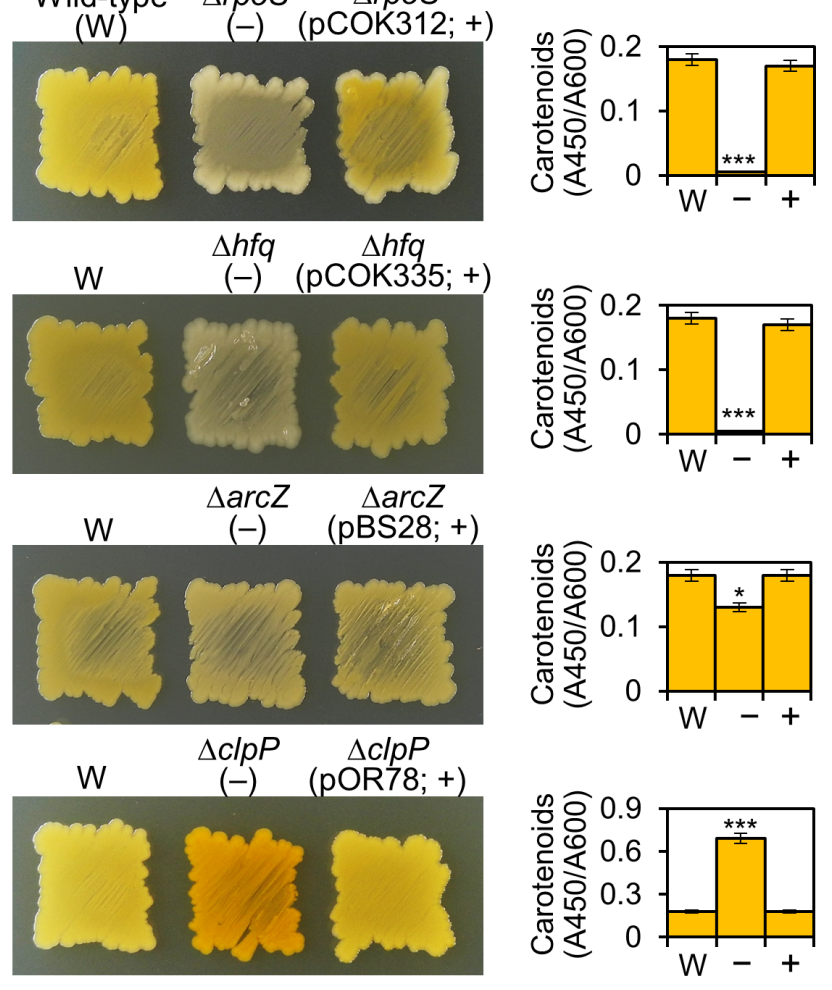




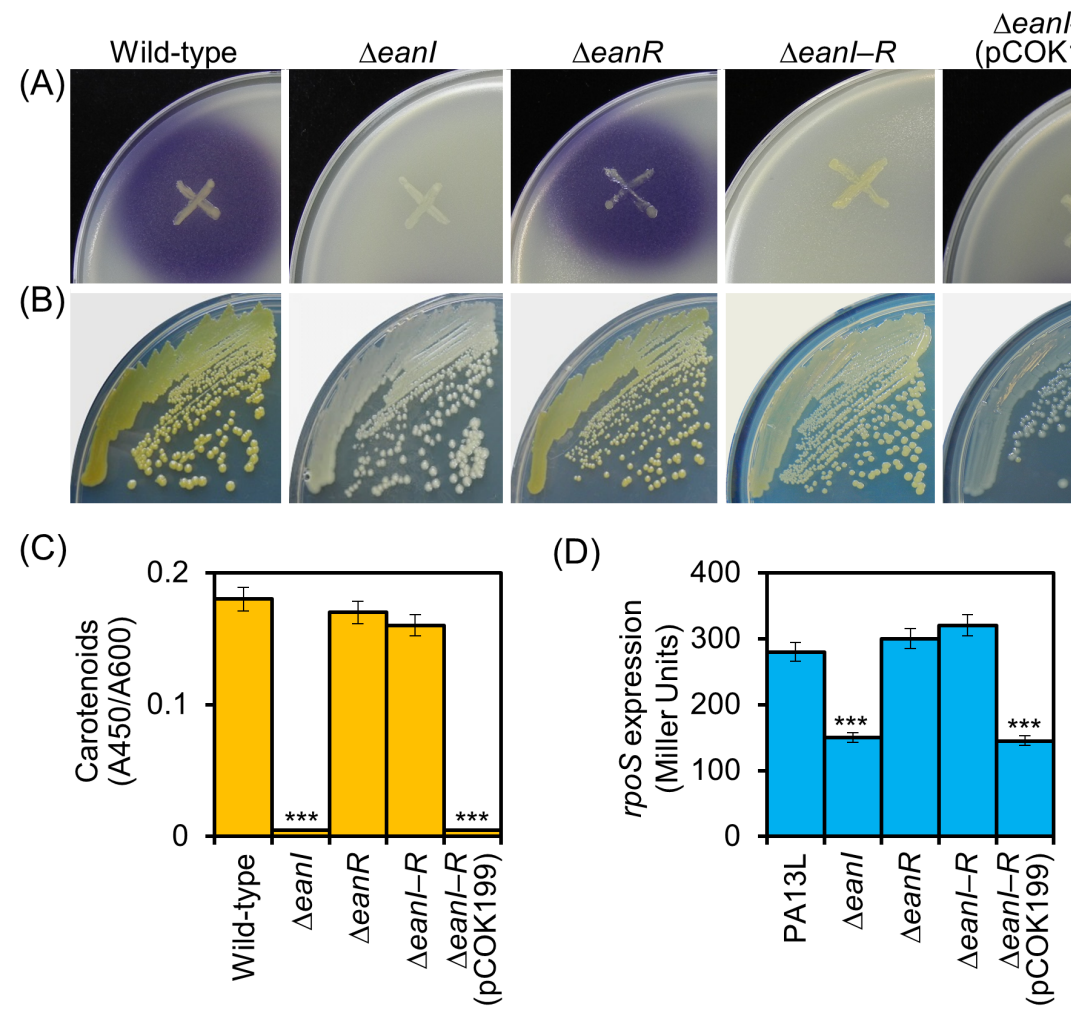

(E)

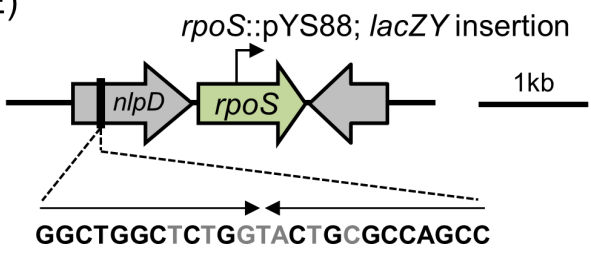


(A)

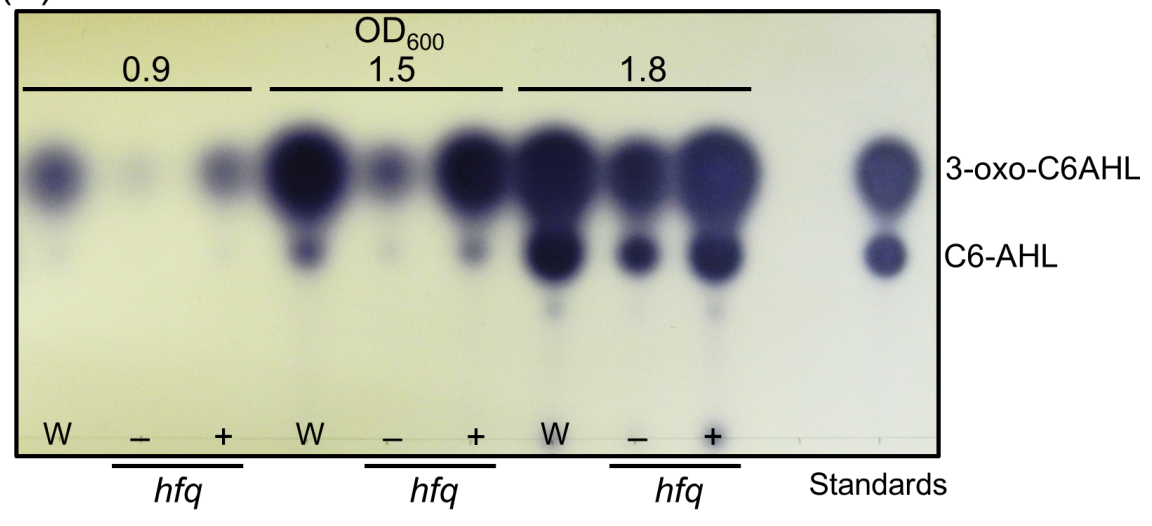

(B)

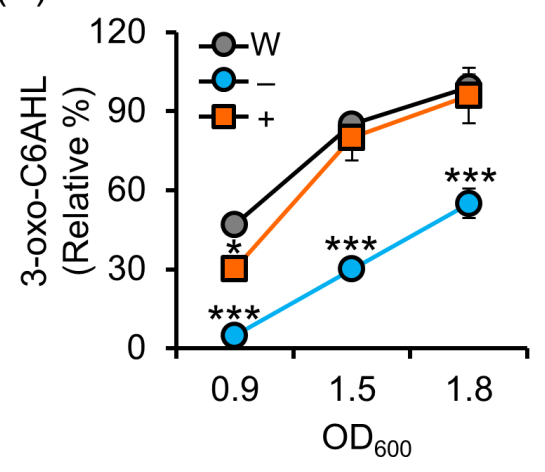

(C)
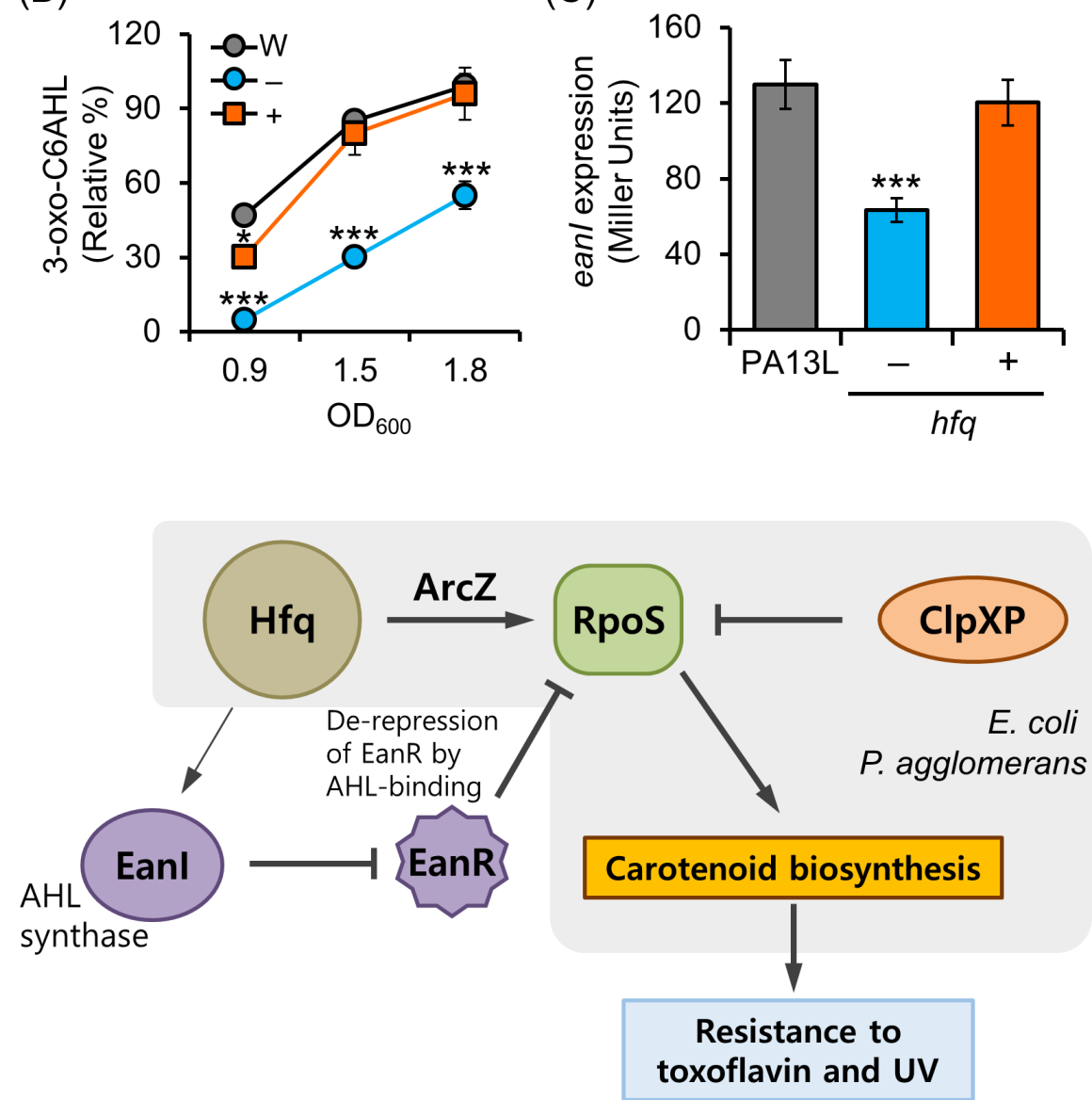